\title{
Biotecnologías reproductivas en el ganado bovino: cinco décadas de investigación en México
}

Jorge Víctor Rosete Fernández ${ }^{\mathrm{a}}$

Horacio Álvarez Gallardo b

David Urbán Duarte ${ }^{b}$

Abraham Fragoso Islas ${ }^{a}$

Marco Antonio Asprón Pelayo ${ }^{\mathrm{c}}$

Ángel Ríos Utrera ${ }^{\mathrm{d}}$

Sandra Pérez Reynozo ${ }^{\mathrm{b}}$

José Fernando De La Torre Sánchez ${ }^{\text {b* }}$

${ }^{a}$ Instituto Nacional de Investigaciones Forestales Agrícolas y Pecuarias (INIFAP). Sitio Experimental Las Margaritas. Km 9.5 carretera federal Hueytamalco-Tenampulco, Hueytamalco, Puebla. México.

b INIFAP. Centro Nacional de Recursos Genéticos. Blvd. De la Biodiversidad No 400, Tepatitlán de Morelos, Jalisco. México.

${ }^{\mathrm{c}}$ Universidad Autónoma de Querétaro. Facultad de Ciencias Naturales. Av. de las Ciencias S/N, Juriquilla, Querétaro. México.

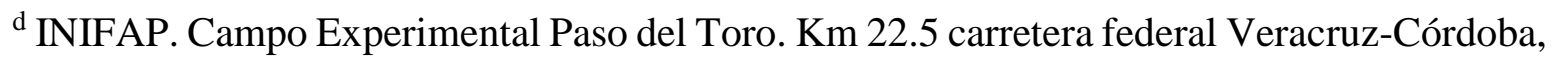
Medellín, Veracruz. México.

* Autor de correspondencia: delatorre.fernando@inifap.gob.mx 


\section{Resumen:}

A lo largo de cinco secciones, se recapitulan las principales biotecnologías reproductivas en el bovino, se analiza su desarrollo histórico, estado actual, y se incluyen resultados generados en México. En la década de 1970, se inició la sincronización estral e inducción de la ovulación donde, basados en el conocimiento de la fisiología reproductiva bovina, se empezó a controlar el ciclo reproductivo con recursos disponibles en aquel entonces. Con los años, la terapia hormonal evolucionó conforme se descubrieron nuevos compuestos, refinando métodos para estandarizar el efecto y generar nuevos métodos de liberación de las hormonas. La biotecnología más usada en el mundo, la inseminación artificial, debe su expansión a los avances en el procesamiento del semen, donde destaca el desarrollo de diluyentes, la criopreservación, el sexado del semen y el análisis espermático asistido por computadora. La era embrionaria inició con el desarrollo de la multiovulación y los métodos para colectar, evaluar, transferir y criopreservar los embriones. La segunda era embrionaria llegó con la producción de embriones completamente in vitro, partiendo de óvulos inmaduros y semen congelado, en lo que se denominó la producción in vitro de embriones. En ésta, se han invertido grandes recursos de investigación, y materiales, para hacerla un pilar del mejoramiento genético y la productividad, en combinación con otras dos herramientas, el semen sexado y las evaluaciones genómicas. Se vislumbra una época de oro de la producción in vitro de embriones con la posibilidad de modificar el genoma de embriones con precisión, gracias a la tecnología de edición de genes.

Palabras clave: Sincronización, Semen sexado, Embriones, Multiovulación, Transferencia de embriones, Producción in vitro, Bovinos.

Recibido: 04/01/2021

Aceptado: 30/04/2021

\section{Introducción}

El texto de la Convención para la Diversidad Biológica (CDB) de la $\mathrm{FAO}^{(1)}$, en funciones desde 1993, establece que el término "biotecnología" se refiere a cualquier aplicación tecnológica que utilice sistemas biológicos, organismos vivos (o sus derivados) para hacer o modificar productos o procesos para un uso específico. En este sentido y para efectos de los temas que serán cubiertos en la presente revisión, se entenderá como biotecnología reproductiva las aplicaciones tecnológicas que incidan en los procesos fisiológicos de la reproducción de los animales, sus gametos y embriones, con el propósito de lograr mejoras productivas. 
El presente documento abarcará únicamente el ámbito de la especie bovina y hará particular énfasis en la investigación realizada por instituciones y universidades en México, particularmente en el Instituto Nacional de Investigaciones Forestales, Agrícolas y Pecuarias (INIFAP), en sus 35 años de existencia, y en su antecesor: el Instituto Nacional de Investigaciones Pecuarias (INIP).

Sin pretender que la presente sea una revisión exhaustiva de todas las biotecnologías reproductivas que se han aplicado en los bovinos, se abordan aquellas que más impacto han tenido en la productividad, y se menciona brevemente las que han tenido mínima o nula aplicación en México, como la transgénesis y la clonación.

Se habla en primera instancia de los temas de sincronización del estro e inducción de la ovulación, por ser tópicos en los que se ha registrado investigación por más tiempo (50 años) y donde el INIP-INIFAP han generado una mayor cantidad de tecnologías. Las biotecnologías desarrolladas para la colección, dilución y criopreservación del semen, han apuntalado el uso masivo de toros de alto mérito genético, a través de la inseminación artificial (IA). Se tocará este tema, haciendo énfasis en desarrollos recientes como el sexado de semen y el análisis espermático asistido por computadora. Los temas relacionados con la manipulación de embriones, incluyendo la multiovulación y transferencia de embriones (MOET, por sus siglas en inglés), la producción in vitro de embriones (PIV) y la obtención de ovocitos por la vía transvaginal (TVA por sus siglas en inglés), han tenido importantes desarrollos en los últimos años, mismos que serán abordados. Además de incluir resultados de investigación en estos temas, en algunos casos se mencionarán programas gubernamentales o de organizaciones de productores que marcaron un hito en la divulgación y adopción de estas biotecnologías reproductivas.

\section{Sincronización estral e inducción de la ovulación}

En el ganado bovino, un problema frecuente es el anestro posparto prolongado, condición que se caracteriza por un retraso en el retorno a la ciclicidad estral después del parto por diversos factores ${ }^{(2-6)}$. Se han hecho muchos esfuerzos para resolver esta condición: se han estudiado tratamientos hormonales para inducir el estro y la ovulación ${ }^{(7,8)}$, controlando el amamantamiento $^{(9,10)}$, la frecuencia y calidad de los estímulos del mismo ${ }^{(11)}$, la alimentación $^{(12)}$ y las diferentes épocas de apareamiento ${ }^{(13)}$. En la presente sección se revisan resultados de inducción de la ovulación en hembras anéstricas y de sincronización del estro y la ovulación en hembras ciclando, realizados por el INIP (1971-1985) y el actual INIFAP (1986-2021), así como por otras instituciones. 


\section{Estudios sobre sincronización estral e inducción de la ovulación}

Los primeros estudios datan de $1948^{(14)}$, cuando se utilizó progesterona (50 mg/d, vía i.m.) para bloquear la ciclicidad estral en un periodo de hasta $13 \mathrm{~d}$ y se observó que, al finalizar su efecto, una buena proporción de hembras presentaban estro a los 4 y 5 d. Más tarde, con la adición de estrógenos al tratamiento, se aumentó la presentación de estros y se redujo el tiempo de bloqueo de la progesterona ${ }^{(15)}$. En los años 70 , se inició el uso de productos hormonales, como el 19 alfa acetoxy-11 beta-methyl-19 nor preg 4 ene 3, 2 diona (progestágeno muy potente conocido como SC21009), la progesterona natural, el valerato de estradiol (VE) y la prostaglandina $\mathrm{F}_{2} \alpha\left(\mathrm{PGF}_{2} \alpha\right)$; en esta época los trabajos se enfocaban en la sincronización estral $^{(16)}$, la resolución del anestro posparto prolongado en vacas y en intentar adelantar la pubertad en vaquillas ${ }^{(17-21)}$. Así, vaquillas de razas europeas, criollas y encastadas de cebú prepúberes, tratadas con 5 mg de VE (i.m.) + 3 mg de SC21009 (i.m.) + 6 mg de SC21009 (implante auricular que se retiró el d 9), tuvieron un $79 \%$ de presentación de estros en las primeras $48 \mathrm{~h}$ de retirado el implante, comparadas con vaquillas testigo, de las cuales sólo el $6 \%$ manifestó estro ${ }^{(21)}$. En otro trabajo ${ }^{(22)}$ con vacas anéstricas y vaquillas encastadas de cebú, se observó que, en las hembras tratadas con progesterona (25 mg por vía i.m. durante 5 días) + cipionato de estradiol (CE; 2 mg por vía i.m. el primer día) o con SC21009 (3 mg durante 5 días en implante subcutáneo) + CE ( 2 mg por vía i.m. el primer día), el estro se sincronizó a las 72 h, con una tasa de estro (TES) de 61.1 y $73.7 \%$, y una tasa de concepción (TC) de 44.4 y $31.3 \%$, respectivamente.

Por el contrario, en las hembras que recibieron los tratamientos testigo e individuales (progesterona, SC21009 o CE) con las mismas dosis, el estro no se sincronizó a las 72 h y tuvieron una TC baja, de 10.5 a $21.1 \%$, durante los 30 días que duró la investigación. En otro experimento ${ }^{(23)}$ con vacas cebú con cría y 60 días posparto, se evaluó la efectividad del SC21009 + VE. En los primeros 48 días, la TES en las vacas tratadas fue $24 \%$ y en las no tratadas $0 \%$, mientras que la TC fue 12 y $0 \%$, respectivamente. Sin embargo, al final del período de IA (día 48) resultaron gestantes $20 \%$ de las vacas tratadas y $12 \%$ de las no tratadas; al final del empadre (día 68; IA + monta natural) se preñaron $28 \%$ de las vacas tratadas, pero sólo $12 \%$ de las no tratadas. Estas TC resultaron ser muy bajas comparado con

lo reportado previamente ${ }^{(22)}$; sin embargo, en vacas cebú sin cría, después de aplicar 6 mg de VE + 3 mg de SC21009 vía i.m. + 6 mg de SC21009 en implante subcutáneo, se observó que el $100 \%$ de las vacas tratadas presentaron estro en las primeras $48 \mathrm{~h}$ después de retirado el implante, en contraste con las vacas no tratadas, de las que sólo $29.4 \%$ presentaron estro. Por su parte, la TC fue $42.8 \%$ en las vacas tratadas y $14.7 \%$ en las no tratadas. Esto indica que la sincronización agrupa los estros para facilitar la IA y el manejo general del hato ${ }^{(24)}$, pero evidencia que es más difícil reducir el periodo de anestro en vacas con cría, circunstancia 
que revela la importancia de disminuir o eliminar el efecto del amamantamiento sobre el retorno a la ciclicidad estral.

\section{Sincronización estral con acetato de melengestrol}

En vacas y vaquillas Suizo Pardo x Cebú se ensayó el uso del progestágeno acetato de melengestrol ( $0.5 \mathrm{mg}$ /día durante 9 días) en el alimento, en combinación con VE (dosis única de $6 \mathrm{mg}$ por vía i.m. el día 1) y progesterona (dosis única de $50 \mathrm{mg}$ el día 1 ). Se observó que el porcentaje de vacas inseminadas a los 48 días de empadre fue 38.9, 51.5 y $75.8 \%$ en las vacas testigo, en las inseminadas convencionalmente a estro detectado, y en las inseminadas a cualquier signo de estro, respectivamente. El porcentaje de vacas inseminadas fue significativamente mayor cuando se realizó ante cualquier signo de estro. Las TC fueron estadísticamente similares entre los tratamientos (20.9, 28.8 y $37.1 \%$, respectivamente), a pesar de que los estros se agruparon en las vacas de cada tratamiento ${ }^{(25)}$. La sincronización del estro con acetato de melengestrol no es una práctica muy difundida en México, a pesar de demostrar su eficacia, lo anterior porque no es práctico realizarla en grupos pequeños de animales y en nuestro país predominan los hatos pequeños.

\section{Sincronización estral con inseminación artificial a tiempo fijo (IATF)}

Debido a que algunas hembras no presentaban estro aun siendo tratadas hormonalmente, se decidió investigar la conveniencia de inseminar en horarios preestablecidos. Así, en vaquillas Brangus y criollas, la IA se realizó en horarios preestablecidos en hembras anéstricas, ya que el porcentaje de animales en estro era muy bajo en los primeros 5 días después de retirado el implante $(53.1 \%)$. Con esta premisa, las vaquillas se inseminaron a las 48, 54 y 60 h después de retirado el implante, con lo que se logró una TC de 54.5, 60.6 y $47.0 \%$, siendo mayores las TC a las 48 y $54 \mathrm{~h}^{(26)}$. Estos resultados dieron la pauta para el inicio de muchos trabajos de sincronización estral con IATF.

Por otro lado, en ganado de carne en pastoreo se hicieron estudios con sincronización estral en épocas de apareamiento (empadres) de 85 días, donde es complicado realizar IA. Así, en clima subtropical húmedo con vacas cebú sin cría, la TES en las primeras 60 h del empadre en vacas tratadas con SC21009 (9 o 6 mg por 9 días) + VE (6 mg el día 1 del tratamiento por 9 días), fue mayor que en las vacas no tratadas (84 vs $0 \%$ ). En forma similar, la TC a los 26 días de empadre favoreció a las vacas tratadas con respecto a las no tratadas (59 vs 40 \%), aunque al término del empadre no existieron diferencias entre tratamientos en la $\mathrm{TC}^{(27)}$. 


\section{Inclusión de la $\mathrm{PGF}_{2} \alpha$ en la sincronización estral}

Con la disponibilidad de la $\mathrm{PGF}_{2} \alpha$, a principios de los años 70, se iniciaron trabajos de sincronización estral en hembras ciclando, confirmando dicho estatus mediante la detección de un cuerpo lúteo ${ }^{(28,29)}$. En vaquillas Brangus, Gyr y Charolais ciclando, tratadas con $\mathrm{PGF}_{2} \alpha$ e inseminadas artificialmente $80 \mathrm{~h}$ después del tratamiento, se obtuvo una TC de $34.8 \%$, que fue similar a la de vaquillas sincronizadas e inseminadas $12 \mathrm{~h}$ después de observado el estro ( $\mathrm{TC}=26.1 \%$ ). Al término del empadre (90 días), en las vaquillas inseminadas a las $80 \mathrm{~h}$, se obtuvo una TC de $69.6 \%$, similar a la TC (56.5 \%) de vaquillas inseminadas artificialmente $12 \mathrm{~h}$ después del estro ${ }^{(30)}$. Los estudios con sincronización estral facilitaron el manejo reproductivo del ganado en pastoreo, ya que ésta permite servir a las hembras en los primeros días del empadre ${ }^{(13,23-26)}$.

\section{Uso del progestágeno norgestomet en la sincronización estral}

El norgestomet (CRESTAR $®$ ), (progestágeno más potente que la progesterona natural), aplicado subcutáneamente en el dorso de la oreja y retirado 9 días después de su implantación, asociado con $\mathrm{VE}$ y $\mathrm{PGF}_{2} \alpha$ (sólo en vacas ciclando), también demostró ser útil en la sincronización estral y la ovulación ${ }^{(31-34)}$. De tal manera que en un estudio ${ }^{(35)}$ con vacas cebú y sus cruzas con europeo, sin cría, en empadre de 63 días (42 días de IA y 21 de monta natural), se lograron, a los 5 días del retiro del implante, TES de 86.1 y $95.0 \%$ en vacas anéstricas y ciclando, respectivamente. Posteriormente, a los 42 días del retiro del implante la TES fue de $100 \%$ en ambos grupos de vacas. Al realizar el diagnóstico de preñez, se determinó que $49.5 \%$ de las vacas anéstricas y $54.0 \%$ de las cíclicas concibieron durante los primeros 5 días de empadre, con los siguientes porcentajes: 90.7 y $98.3 \%$ a los 42 días; y al término del empadre (63 días), con la presencia del toro desde el día 43 hasta el final del mismo, de $96.2 \%$ y $98.3 \%$, respectivamente. Este estudio demostró la utilidad de la inducción y sincronización del estro en vacas en épocas de empadre (principalmente las anéstricas) que, de lo contrario, se retrasarían hasta 21 días para concebir. Los resultados con el implante auricular SC21009 combinado con VE, para realizar IATF a las 56-60 h después de retirado el implante (día 9), también fueron atractivos, pues se logró una TES de $95 \%$ y una TC de $85 \%$ en empadres de 45 días $^{(36)}$.

\section{Uso del dispositivo intravaginal liberador de progesterona (CIDR) en la sincronización estral}

Con la introducción en el mercado del CIDR la sincronización estral revolucionó ${ }^{(37)}$, por lo

que investigadores del INIFAP ${ }^{(38,39)}$ incursionaron en su uso en vacas en anestro y ciclando, con buena condición corporal (CC), obteniendo una TC de 44.8, 77.1 y $100.0 \%$ a los 3, 30 y 60 días post-retiro del CIDR, respectivamente ${ }^{(38)}$. En vaquillas Bos taurus x Bos indicus ${ }^{(39)}$, 
la TC con CIDR e IATF a las $84 \mathrm{~h}$ después del retiro del dispositivo fue mayor que con IA convencional a las $12 \mathrm{~h}$ de detectado el estro (36.4 vs 18.2\%, respectivamente); similarmente, la TC con CRESTAR e IATF a las $84 \mathrm{~h}$ después del retiro del dispositivo fue mayor que con IA convencional ( 27.3 vs $18.2 \%$, respectivamente). En este trabajo se demostró la ventaja de la IATF a las $84 \mathrm{~h}$ después el retiro del dispositivo, ya que lograron preñeces en algunas vaquillas que no manifestaron estro. Una práctica frecuente en los protocolos de sincronización del estro y la ovulación con IATF en los que se utiliza el CIDR y la $\mathrm{PGF}_{2} \alpha$, asociados con benzoato de estradiol (BE) (el cual se aplica al insertar el CIDR el día 0 y al día siguiente de su retiro, es decir, el día 8), es la sustitución del BE por la GnRH, pues la $\mathrm{GnRH}$, al igual que el $\mathrm{BE}$, sincroniza la emergencia de una nueva ola de desarrollo folicular, que culmina en la ovulación del folículo maduro, dando buenos resultados; sin embargo, si se sospecha que hay una proporción importante de vacas en anestro, se recomienda aplicar adicionalmente 400 UI de gonadotropina coriónica equina (eCG) el día 7 del protocolo. Además, el BE puede ser sustituido por la GnRH (100 $\mu$ g i.m.), en la primera aplicación (día 1 del CIDR), pero la segunda se realiza al momento de la IATF. En la Figura 1 se esquematiza un ejemplo para vacas ciclando ${ }^{(40)}$.

\section{Importancia de la condición corporal en la inducción y sincronización estral}

Se ha demostrado que la condición corporal (CC) es un indicador del estado nutricional de la vaca y que, si ésta tiene buena CC antes y después del parto, mejora su fertilidad, gestándose pronto después del parto ${ }^{(41)}$. Además, se ha demostrado que ésta se asocia con altas concentraciones del factor de crecimiento semejante a la insulina tipo 1 (IGF-1), leptina e insulina, lo que permite el reinicio temprano de la actividad estral posparto ${ }^{(42)}$. Por lo tanto, otras investigaciones se enfocaron en estudiar los cambios en la concentración sanguínea de estas tres hormonas, como indicadores metabólicos del estado nutricional de los animales, observándose que una baja CC en las hembras ( $<6.0$ unidades; escala 1 a 9), se asocia con reducción en la concentración sanguínea de la insulina e IGF-1, sin cambios en la leptina, reduciendo la respuesta a la inducción del estro posparto en vacas de carne ${ }^{(43,44)}$. Por lo tanto, las hembras que son sincronizadas e ingresan al empadre deben tener buena CC (no menor a 6.0), para favorecer la presentación de estros y lograr la gestación ${ }^{(45)}$.

\section{La kisspeptina en la sincronización estral e inducción de la ovulación}

Las kisspeptinas son péptidos que por su número de aminoácidos se denominan: kisspeptina54, kisspeptina-14, kisspeptina-13 y kisspeptina-10 $0^{(46)}$. Las neuronas sintetizadoras son consideradas como integradoras de señales que modulan la funcionalidad del eje somatotrópico y gonadal ${ }^{(47)}$. En estudios con la kisspeptina-10 (kiss-10) intravenosa (5 $\mu \mathrm{g} / \mathrm{kg}$ de peso) se produjeron aumentos en la secreción de LH, FSH y hormona del crecimiento en 
becerras y becerros prepúberes ${ }^{(48,49)}$, observándose que en todas las becerras aumentó la $\mathrm{LH}$ con la edad, con valores promedio de 6.1, 7.2 y $11.6 \mathrm{ng} / \mathrm{ml}$ a los 4,7 y 11 meses de edad, respetivamente ${ }^{(50)}$. La mayor concentración de LH se presentó en las becerras de 11 meses de edad.

Con la intención de conocer la sensibilidad del eje gonadotrópico a la kiss-10, en otros estudios se probaron dosis intravenosas de $0.1,1.0,2.0,3.0,4.0$ y $5.0 \mu \mathrm{g} / \mathrm{kg}$ de peso $^{(51)}$ y de $50.0 \mu \mathrm{g} / \mathrm{kg}^{(52)}$ en becerras prepúberes, resultando que las dosis efectivas para inducir la liberación de LH fueron desde 1.0 hasta $5.0 \mu \mathrm{g} / \mathrm{kg}$. Por lo tanto, la aplicación de dosis bajas, menores a $5 \mu \mathrm{g} / \mathrm{kg}$ de peso, podrían reducir considerablemente el costo del tratamiento con dicho péptido ${ }^{(51)}$. En un siguiente experimento con becerras prepúberes en el que se usó kiss10 en dosis de $5 \mu \mathrm{g} / \mathrm{kg}$ de peso, aplicada cada $2 \mathrm{~h}$ durante $84 \mathrm{~h}$ ( 3.5 días), se logró inducir la ovulación y la formación de un cuerpo lúteo en $28.5 \%$ de las becerras, aunque después el cuerpo lúteo desapareció y las becerras volvieron a su estado prepuberal ${ }^{(53)}$. Más tarde, se comprobó que en vacas para producción de carne (europeo x cebú), con 78 días posparto, anéstricas y amamantando a su cría, la kiss-10 a una dosis de $1 \mu \mathrm{g} / \mathrm{kg}$ de peso cada $2 \mathrm{~h}$ durante 24 h también incrementó la concentración de LH sérica, aumento que emuló un pulso breve de $\mathrm{LH}^{(54)}$. Este resultado promovió un estudio de sincronización de la ovulación, de tal manera que se probó la kiss-10 en dosis total de $500 \mu \mathrm{g}$ en el momento de la IATF, comparándola con GnRH (100 $\mu \mathrm{g}$ en el momento de la IATF) y eCG (400 UI al retirar el CIDR el día 7), en un protocolo en que cada hormona se combinó con CIDR, BE ( 2 mg al aplicar el CIDR + $1 \mathrm{mg}$ al día siguiente de retirado el CIDR) y cloprostenol (dosis total de $500 \mu \mathrm{g}$ al retirar el CIDR), en vacas de carne, sin cría y con 180 días posparto, inseminadas entre 54 y 56 h después de retirar el CIDR. La tasa de ovulación para los tratamientos con eCG, GnRH y kiss-10 fue 89.2, 96.5 y $93.8 \%$, mientras que la de concepción fue 43.6, 73.8 y $54.3 \%$, respectivamente, sin existir diferencias estadísticas significativas entre tratamientos en ninguno de los dos casos ${ }^{(55)}$. Este resultado podría ser de interés para la industria farmacéutica, como una alternativa para la sincronización e inducción de la ovulación.

Figura 1: Esquema general de la sincronización estral en vacas y vaquillas con $\operatorname{IATF}^{(40)}$
Inserción del
Retiro del CIDR
CIDR, $1.9 \mathrm{~g}$
+ PGF2 $\alpha, 25$ mg i.m.
+ BE, 2 mg i.m.
BE, $1 \mathrm{mg}$ i.m.
IATF

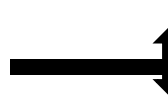
Día 0
Día 7
Día 8
Día 9 
En conclusión, la sincronización estral e inducción de la ovulación en ganado bovino en clima tropical, revolucionó el manejo reproductivo, pues permitió concentrar los estros entre 52 y $56 \mathrm{~h}$ después del retiro del CIDR en una época de empadre con IATF, de tal manera que facilitó el uso de la IA, con la posibilidad de volver a inseminar a estro manifiesto a las hembras que no concibieron al primer servicio, aumentando el número de vacas gestantes con IA, lo que sin duda favorece genéticamente al hato.

\section{Procesamiento de semen e inseminación artificial}

La IA fue la primera biotecnología reproductiva aplicada para mejorar la producción a través del uso más eficiente de toros de alto mérito genético. El uso generalizado de esta técnica y el logro de su completo potencial requirió de la criopreservación del semen por largos periodos de tiempo.

El primer reporte de criopreservación de semen se realizó en $1776^{(56)}$, donde se observó que cuando los espermatozoides de humano, garañón y rana eran enfriados en nieve hasta $30 \mathrm{~min}$ se volvían inactivos, pero podían ser reactivados. En $1940^{(57)}$, se comenzó a utilizar la yema de huevo para proteger a las células espermáticas de toro del choque térmico al enfriarse. En $1941^{(58)}$, se mejoraron los diluyentes espermáticos mediante el uso de yema de huevo con citrato de sodio, lo que permitió la conservación del semen a $5{ }^{\circ} \mathrm{C}$ durante un máximo de 3 días. En 1949, se congelaron por primera vez los espermatozoides de toro mediante el uso de glicerol en el diluyente. El gran descubrimiento de la acción crioprotectora del glicerol abrió una era exitosa en la criopreservación no sólo de gametos de varias especies, sino también de otras células y tejidos ${ }^{(59)}$. El llamado diluyente Cornell, creado por Foote y Bratton en $1950^{(60)}$, contenía una mezcla de los antibióticos penicilina, estreptomicina y polimixina B y fue utilizado durante muchos años como estándar. En 1952, en Cambridge, nació el primer ternero después del uso de semen bovino congelado-descongelado ${ }^{(61)}$.

Los reportes de fertilidad con espermatozoides congelados de toro condujeron a un intenso desarrollo de métodos de criopreservación para tratar de mejorar los resultados obtenidos, por lo que se empezaron a usar otras disciplinas (como la biología molecular) asociadas al proceso de criopreservación. Tal es el caso de la proteómica ${ }^{(62)}$ y la ingeniería genética ${ }^{(63)}$. En estos temas, en México se realizó un trabajo con personal del INIFAP, donde se evaluó la adición del FAA recombinante (antígeno asociado a la fertilidad, por sus siglas en inglés) y TIMP-2 recombinante (inhibidor tisular de metaloproteinasas 2 , por sus siglas en inglés) al semen congelado de bovino, con lo que se logró incrementar significativamente su fertilidad $^{(64)}$. 


\section{Sexado espermático}

Los avances obtenidos con la IA generaron el interés de utilizarla para seleccionar el sexo en el ganado lechero. Por este motivo, a lo largo del tiempo, muchos investigadores trataron de separar los espermatozoides con cromosomas " $\mathrm{X}$ " $\mathrm{y}$ " $\mathrm{Y}$ " mediante varias técnicas ${ }^{(65)}$. A partir de la década de 1980, comenzó a aplicarse la citometría de flujo, la cual permitió separar los espermatozoides de acuerdo con sus cromosomas sexuales y cantidad de ADN. Tomó alrededor de 20 años que esta tecnología fuera comercializada para su uso en IA en ganado bovino. Esta técnica se basa en que los espermatozoides que presentan cromosoma " $\mathrm{X}$ " en el bovino contienen $3.8 \%$ más ADN que los "Y"(66). Esta tecnología tenía una eficacia de 85 a $95 \%$ (en cuanto a la separación de espermatozoides con cromosoma X o Y), sin embargo, no estaba completamente perfeccionada ${ }^{(67)}$.

La primera producción comercial de semen sexado fue en la compañía Cogent en Reino Unido $^{(65)}$. Aunque tuvo un inicio relativamente lento, aumentó exponencialmente la producción de semen sexado bovino con un estimado de 4 millones de dosis en $2008^{(68)}$.

El semen sexado se comercializaba en pajillas de $0.25 \mathrm{ml}$ a una concentración de 2.1 millones de espermatozoides ${ }^{(69)}$. Esta concentración se debía a que, al momento de sexar el semen, se perdía aproximadamente $80 \%$ del eyaculado entre los espermatozoides del sexo no deseado y los espermatozoides que no se lograban diferenciar, además del prolongado tiempo que tardaba el proceso de separación ${ }^{(70)}$. A pesar de las limitantes del semen sexado, claramente hubo una buena aceptación ${ }^{(68)}$. Se consiguieron porcentajes de gestación aceptables con la dosis reducida (2.1 x $10^{6}$ espermatozoides) de semen sexado en vaquillas, pero se realizaron pocos trabajos con vacas lactantes ${ }^{(66)}$. En la actualidad, la tecnología del sexado espermático ha evolucionado, modificando las técnicas, incrementando la velocidad del sexado, disminuyendo el estrés sobre los espermatozoides, aumentando la concentración y, por ende, mejorando los parámetros de viabilidad espermática.

\section{IA con dosis baja de semen sexado}

En 1997 se realizó una investigación con dos objetivos: 1) evaluar las tasas de concepción de vaquillas inseminadas (en el cuerno uterino, ipsilateral al ovario con folículo de mayor tamaño) con dosis reducidas de semen $\left(1 \times 10^{5} ; 2.5 \times 10^{5} ; 2.5 \times 10^{6}\right.$ espermatozoides $/ 0.21$ $\mathrm{ml}$ ) refrigerado a $5{ }^{\circ} \mathrm{C}$ bajo condiciones ideales a nivel de campo; 2) evaluar las tasas de concepción de vaquillas inseminadas (en el cuerno uterino, ipsilateral al ovario con folículo de mayor tamaño) con dosis reducidas de semen sexado (1-2 x10 espermatozoides $/ 0.1 \mathrm{ml})$ refrigerado a $5{ }^{\circ} \mathrm{C}$. En el experimento 1 los porcentajes de gestación a los 40 días fueron de 41,50 y $61 \%$ para $1 \times 10^{5} ; 2.5 \times 10^{5} ; 2.5 \times 10^{6}$ espermatozoides/IA respectivamente. En el experimento 2, de 67 vaquillas inseminadas $22 \%$ resultaron gestantes y $82 \%$ de las crías 
fueron del sexo seleccionado ${ }^{(71)}$. La investigación realizada indica que la IA con dosis de semen menores a las convencionales es posible cuando se usa semen sexado, siendo lo más común utilizar $2.1 \times 10^{6}$ espermatozoides en la dosis de inseminación, contra al menos $10 \times 10^{6}$ que se emplea con semen no sexado.

\section{Criopreservación exitosa del semen sexado}

Posteriormente, en 1999, se llevó acabo otra investigación con el objetivo de evaluar el proceso de congelación del semen sexado; esto se logró debido a que el semen se procesó en un citómetro de flujo MoFlow $\mathrm{SX}^{\mathrm{TM}}$, con lo cual se pudo tener suficiente cantidad de espermatozoides, a diferencia de cuando se trabajó con el citómetro de flujo EPICS V. En este trabajo se determinó que el uso del láser a una potencia de $100 \mathrm{~mW}$ tenía un menor impacto sobre la motilidad progresiva del semen post-descongelado que cuando se utilizó a $150 \mathrm{~mW}$. También se observó que la motilidad progresiva post-descongelado fue superior cuando se usó un diluyente en base a TRIS que cuando se utilizó citrato-yema de huevo o TEST. En cuanto al tiempo de equilibrio (adaptación al crioprotector) a $5{ }^{\circ} \mathrm{C}$ previo a la congelación, se concluyó que fue mejor la motilidad progresiva post-descongelado de 3 a 6 h que cuando duró $18 \mathrm{~h}$. Por otra parte, se determinó que fue mejor mantener de 4 a $7 \mathrm{~h}$ el semen fresco a $22{ }^{\circ} \mathrm{C}$ que diluirlo con el medio TALP adicionado con el fluorocromo Hoechst 33342. Con estos nuevos procedimientos para el sexado espermático se consiguieron resultados ligeramente menores que con semen convencional en cuanto a motilidad e integridad acrosomal. Con estos resultados se consideraba que el uso de semen sexado para IA de forma comercial estaría disponible en, aproximadamente, 2 años ${ }^{(72)}$.

\section{Inicios de la comercialización del semen sexado}

La compañía Monsanto ubicada en St, Louis, Mo, USA, desarrolló un sistema de selección espermática único en su clase, el cual utilizaba 16 boquillas de selección en vez de una sola como en el caso de los citómetros MoFlow $\mathrm{SX}^{\mathrm{TM}}$. Se pretendía comercializar este equipo, pero, al parecer, debido a problemas con bajos porcentajes de concepción que se detectaron en sus primeras pruebas, la compañía desistió. En 2003, Genetic Resources International/Sexing Technologies en Navazota TX, USA compró la propiedad intelectual y el equipo de sexado espermático desarrollado por Monsanto y toda la infraestructura de XY Inc (primera compañía que tuvo la propiedad intelectual del sexado espermático y fue la creadora de los citómetros $\left.\mathrm{MoFlow}^{\mathrm{TM}}\right)^{(69)}$. Actualmente, la compañía cambió su nombre a STgenetics ${ }^{\circledR}{ }^{(72)}$. 


\section{Semen sexado SexedULTRATM}

La diferencia en la fertilidad entre el semen convencional y el semen sexado no mejoró al aumentar la concentración espermática por IA. Las causas de una menor fertilidad del semen sexado se han atribuido a los diversos cambios bioquímicos a los que se someten los espermatozoides durante el sexado. La tecnología XY descrita en previas publicaciones ${ }^{(73,74)}$ se modificó, ahora es un sistema de sexado totalmente nuevo llamado SexedULTRA ${ }^{\mathrm{TM}}$ (Navazota, TX, USA). La tecnología SexedULTRA ${ }^{\mathrm{TM}}$ se ha diseñado para ser más inocua para el espermatozoide durante los puntos más críticos del proceso, mejorando particularmente los cambios de $\mathrm{pH}$ (sistema buffer) y estrés oxidativo.

\section{Modificaciones a la técnica de sexado SexedULTRA ${ }^{\mathrm{TM}}$}

Aunque en la actualidad existen muy pocos datos acerca de esta nueva tecnología, se ha reportado que se facilita el ingreso del fluorocromo Hoechst 33342 y se retiene dentro de la célula, lo que permite que haya mayor fluorescencia y con esto se logre una mejor discriminación entre las poblaciones " $X$ " y "Y". Se modificó el protocolo, con un tratamiento previo al proceso de tinción, además del uso de un nuevo medio de tinción que mantiene el $\mathrm{pH}$ estable durante un periodo de tiempo más prolongado. El medio de congelamiento también se modificó, tomando en cuenta la dosis de semen sexado por pajilla ${ }^{(72)}$.

En el éxito del proceso de ultrasexado influyeron principalmente dos factores: las modificaciones en los medios y los equipos para realizar el sexado. Los citómetros MoFlo $\mathrm{SX}^{\mathrm{TM}}$ (Cytomation Inc, Fort Collins, CO, USA) eran equipos muy costosos, voluminosos, tenían bajo rendimiento y requerían de personal altamente capacitado para operarlos. Los modernos citómetros Genesis desarrollados por Cytonome ST ${ }^{\mathrm{TM}}$ (Boston, MA, USA) tienen características electrónicas avanzadas y automatizadas con múltiples cabezas en una máquina para una separación paralela. El citómetro Genesis III ${ }^{\mathrm{TM}}$, utiliza un láser de estado sólido, dos detectores ortogonales ( $0^{\circ}$ y $90^{\circ}$ con respecto al láser), una boquilla de orientación y una separación de subpoblaciones de $\sim 8000$ espermatozoides/segundo con $\sim 90 \%$ de pureza, alcanzando un máximo de separación de 500 millones de espermatozoides $/ \mathrm{h}^{(75)}$.

\section{Pruebas de laboratorio de la tecnología SexedULTRA ${ }^{\mathrm{TM}}$}

Con las modificaciones mencionadas se incrementó la motilidad espermática, así como la integridad del acrosoma con respecto a la tecnología XY Legacy (sexado convencional) considerando las mismas concentraciones espermáticas ${ }^{(76)}$.

Por otra parte, en $2018^{(77)}$, se evaluó la calidad espermática considerando: integridad de la membrana plasmática, porcentaje de acrosomas intactos y el índice de fragmentación de 
DNA del semen SexedULTRA ${ }^{\mathrm{TM}}$ comparado con el semen convencional (no sexado). En el semen SexedULTRA ${ }^{\text {TM }}$ a las $3 \mathrm{~h}$ post-descongelado, el porcentaje de acrosomas intactos fue significativamente mayor con respecto al semen convencional. Además, el semen SexedULTRA ${ }^{\mathrm{TM}}$ tuvo un índice de fragmentación del DNA significativamente menor en todos los puntos de evaluación con respecto al semen convencional. Los autores concluyen que la tecnología SexedULTRA ${ }^{\mathrm{TM}}$ mantiene la calidad del semen y, en muchos casos, tiene mayor longevidad in vitro comparado con el semen convencional.

\section{Pruebas de campo de la tecnología SexedULTRA ${ }^{\mathrm{TM}}$}

En la primera evaluación a nivel de campo utilizando la tecnología SexedULTRA ${ }^{\mathrm{TM}}$ para IA $^{(78,79)}$, hubo un incremento del $7.4 \%$ en las tasas de concepción de vaquillas con respecto a la tecnología XY Legacy (sexado convencional). La segunda prueba se realizó en colaboración con la compañía comercial Select Sires, en esta prueba se utilizaron ocho toros de los cuales se colectó semen y se procesó utilizando tanto la tecnología SexedULTRA ${ }^{\mathrm{TM}}$ como la tecnología XY Legacy, con lo que se inseminaron 6,930 vaquillas. Los resultados mostraron que el semen SexedULTRA ${ }^{\mathrm{TM}}$ incrementó $4.5 \%$ la tasa de concepción con respecto al semen XY Legacy, 46.1 y $41.6 \%$ respectivamente.

Con estas pruebas se observó que los efectos deletéreos de la tecnología XY Legacy fueron parcialmente aminorados con la nueva tecnología SexedULTRA ${ }^{\mathrm{TM}}$, por lo que el siguiente paso lógico fue incrementar la concentración espermática por dosis, aunque en el pasado el aumento en la concentración espermática no mejoró la fertilidad. La siguiente prueba se realizó en colaboración con la compañía German Genetics International, se colectó semen de cinco toros, cada eyaculado se dividió en 4 partes y se procesó con la tecnología XY Legacy de 2.1 millones de espermatozoides, SexedULTRA ${ }^{\text {TM }}$ de $2.1,3$ y 4 millones de espermatozoides por dosis. Además, se utilizó semen de estos mismos toros de eyaculados contemporáneos congelados de forma convencional, con una concentración de 15 millones de espermatozoides por dosis. Se calcularon las tasas de no retorno al estro (NRR) a 65 días a partir de 7,855 IA con semen sexado y 62,398 IA con semen convencional. En general, el semen XY Legacy de 2.1 millones de espermatozoides por dosis resultó en menores NRR (55.9\%) comparado con todos los tratamientos de SexedULTRA ${ }^{\text {TM }}$ (2.1 millones 59.9; 3.0 millones $60.0 \% ; 4.0$ millones $66.7 \%$ ) y semen convencional $(65.7 \%)$. Los tratamientos de SexedULTRA ${ }^{\mathrm{TM}}$ de 2.1 y 3 millones de espermatozoides por dosis fueron similares (59.9 y $60.0 \%$ respectivamente), pero menores que el semen convencional (65.66 \%); sin embargo, el tratamiento de SexedULTRA ${ }^{\mathrm{TM}}$ de 4 millones de espermatozoides por dosis tuvo NRR similares al semen convencional de 15 millones de espermatozoides por dosis ${ }^{(79)}$. Con los datos obtenidos se demostró por primera vez el efecto de la dosis respuesta utilizando semen sexado. 


\section{Pruebas de campo con la tecnología SexedULTRA-4MTM}

Se evaluó el uso del semen SexedULTRA-4M ${ }^{\mathrm{TM}}$ en $\operatorname{IATF}^{(80)}$ utilizando vacas y vaquillas de carne. Los resultados muestran que no hubo diferencia significativa en cuanto al porcentaje de preñeces entre el semen convencional (61.9\%) y el semen SexedULTRA-4M ${ }^{\mathrm{TM}}(63.8 \%)$ cuando las hembras presentaron celo antes de la IATF.

En otro experimento ${ }^{(81)}$ se comparó el uso de semen convencional y semen SexedULTRA$4 \mathrm{M}^{\mathrm{TM}}$ en IA utilizando tres toros diferentes y vacas de carne. En este estudio, se encontró que la fertilidad está influenciada por el toro, ya que sólo uno de tres toros no tuvo diferencias en cuanto al porcentaje de gestaciones al comparar el semen convencional y el SexedULTRA$4 \mathrm{M}^{\mathrm{TM}}$, lo cual muestra que existe diferencia entre toros, así como con el semen sexado Legacy.

Existe poca investigación sobre la efectividad del uso de semen sexado en México, aunque ya está disponible por varias compañías procesadoras de semen y es de uso rutinario, sobre todo en unidades de producción lecheras. En los experimentos se ha usado semen sexado Legacy y se ha encontrado que funciona tanto para vacas como para vaquillas Holstein, con una tasa de preñez de entre 80 a $90 \%$ de la que se registra en hembras inseminadas con semen convencional y con valores de entre 85 a $93.6 \%$ de crías nacidas con el sexo predicho ${ }^{(82-85)}$. También se comprobó que el uso del semen sexado no influye en la presentación de abortos ni de partos distócicos ${ }^{(86)}$.

\section{Evaluación espermática asistida por computadora}

La fertilidad es un evento multiparamétrico relacionado con la calidad y cantidad del semen, el tiempo exacto y método de IA, la fertilidad intrínseca del toro y un adecuado manejo del hato ${ }^{(87)}$. La morfología, motilidad, viabilidad, concentración e integridad del acrosoma y del DNA han sido usados como parámetros para evaluar la calidad espermática de semen de bovinos $^{(87-90)}$. Algunos de estos parámetros (como la morfología y motilidad) se pueden evaluar de forma manual a través de métodos convencionales que usan un microscopio de luz visible. Sin embargo, esas evaluaciones están sujetas a criterios subjetivos y errores técnicos que disminuyen su precisión y repetibilidad.

A mediados de los años 1980, los sistemas de análisis de espermatozoides asistidos por computadora (CASA por sus siglas en inglés) fueron introducidos de forma comercial para maximizar la precisión y repetibilidad de las evaluaciones de semen ${ }^{(91)}$. Estos sistemas CASA tienen como principal función la evaluación objetiva de la calidad seminal. Los componentes básicos de esta tecnología consisten en un microscopio para visualizar la muestra, una cámara 
digital para la captura de imágenes y una computadora con un software especializado que analiza las imágenes.

La motilidad es una de las características más importantes del espermatozoide asociadas con la habilidad de fertilizar ${ }^{(92)}$. Con el uso del sistema CASA, se obtienen diversos parámetros de motilidad que describen movimientos específicos del espermatozoide. Los porcentajes de motilidad total y progresiva son los parámetros más importantes en la evaluación de la cinética de los espermatozoides ${ }^{(87)}$. La motilidad total se refiere a la fracción de espermatozoides que muestran cualquier tipo de movimiento, mientras que los espermatozoides con motilidad progresiva tienen un movimiento hacia adelante, esencialmente en línea recta.

Existen otros parámetros cinéticos específicos determinados por el sistema CASA que son útiles para evaluar varias características espermáticas de forma simultánea y objetiva. Estos parámetros cinéticos se componen principalmente por tres valores de la velocidad de movimiento, tres índices de velocidad y tres parámetros que reflejan las características de oscilación de los espermatozoides ${ }^{(93)}$. Los tres valores de la velocidad de movimiento son la velocidad curvilínea (VCL), la velocidad rectilínea (VSL) y la velocidad media de trayectoria (VAP). A partir de estos tres valores se calculan tres índices, la linealidad (LIN=VSL/VCL), la rectitud (STR=VSL/VAP) y la oscilación de las trayectorias (VAP/VCL), con lo que queda caracterizada la calidad del movimiento espermático. Los parámetros que muestran las características de oscilación de los espermatozoides son el desplazamiento lateral de la cabeza, la frecuencia de batido de la cola y la media del desplazamiento angular.

Los parámetros de movimiento del sistema CASA se han usado para la identificación de subpoblaciones de espermatozoides y su posterior correlación con la resistencia a la congelación ${ }^{(94,95)}$. Además, se han evaluado los efectos de diferentes medios durante el procesamiento in vitro sobre la función de los espermatozoides ${ }^{(96)}$.

Por otra parte, con el uso del sistema CASA, diversos grupos han reportado una correlación significativa entre la motilidad total $(\mathrm{r}=0.26-0.61)$ y progresiva $(\mathrm{r}=0.26-0.33)$ del semen de toros, y su fertilidad asociada al campo ${ }^{(97-101)}$. El sistema CASA colecta un amplio rango de parámetros de la cinética espermática. Algunos grupos de investigación mostraron una correlación positiva entre la VSL ( $\mathrm{r}=0.17-0.67)$, la LIN ( $\mathrm{r}=0.28-0.46)$ y la STR $(\mathrm{r}=0.33)$, y la fertilidad en campo $^{(98,102,103)}$. Las correlaciones entre los parámetros de motilidad y la fertilidad tienden a ser de bajas a medias y no se recomienda su uso de forma aislada para predecir la fertilidad de una muestra de semen ${ }^{(101-103)}$. Sin embargo, la combinación de varios parámetros de motilidad proporciona una herramienta mejor para predecir la fertilidad, ya que la regresión de múltiples parámetros del sistema CASA explicó hasta el 0.98 (valor de $\mathrm{r}^{2}$ ) de la variación de la fertilidad, comparado con el 0.34 explicado sólo por la motilidad total ${ }^{(103)}$. Por otro lado, recientes análisis del movimiento espermático en tercera dimensión, 
así como el estudio del movimiento flagelar representarían nuevos parámetros funcionales que podrían ser relacionados con la fertilidad ${ }^{(104)}$.

La morfología de los espermatozoides es una de las pruebas más importantes del control de calidad del semen, ya que refleja el estado fisiológico o patológico de la funcionalidad de los testículos, epidídimo y glándulas accesorias de los reproductores ${ }^{(105)}$; además, es considerada como una mejor prueba para evaluar las características genéticas y del DNA del espermatozoide comparada con la motilidad ${ }^{(106,107)}$. Diversos estudios han mostrado una correlación significativa entre la morfología espermática $(\mathrm{r}=0.22-0.76)$ y la fertilidad en campo $^{(94,98,108)}$. Sin embargo, la mayoría de los análisis morfológicos se realizan a través de métodos convencionales, lo que permanece como una problemática debido a la subjetividad en la evaluación, así como a la inconsistencia observada intra e inter técnicos ${ }^{(109,110)}$. Por tal motivo, el análisis morfológico no se ha considerado confiable en la predicción de la fertilidad en campo ${ }^{(94,98)}$. El desarrollo de módulos específicos para el análisis morfológico de los espermatozoides dentro del sistema CASA ha permitido la evaluación individual de características morfométricas de la cabeza del espermatozoide en cuanto a tamaño (área, perímetro, longitud y anchura) y forma (elipticidad, elongación, regularidad y rugosidad) ${ }^{(111)}$. Algunos sistemas ofrecen incluso información sobre la pieza intermedia (área y anchura) y datos referentes a la inserción de la pieza intermedia en la cabeza, como son la distancia y el ángulo de la inserción ${ }^{(112)}$. Dentro de estos parámetros, la anchura de la cabeza de los espermatozoides mostró una correlación significativa $(\mathrm{r}=0.53)$ con la fertilidad en campo ${ }^{(113)}$. Por otro lado, se han reportado subpoblaciones de espermatozoides basadas en su estructura morfométrica $^{(114)}$. La evaluación de nuevos parámetros, así como la identificación de subpoblaciones de espermatozoides podría proveer información sobre una población óptima que mejore la fertilidad ${ }^{(90)}$.

Existen otros parámetros que estudian la función espermática, tales como la vitalidad, integridad del acrosoma y fragmentación del DNA. La viabilidad clasifica los espermatozoides como vivos o muertos y muestra la existencia de daño en la membrana plasmática del espermatozoide ${ }^{(115)}$. La integridad del acrosoma es una de las pruebas funcionales espermáticas más importantes, ya que sólo un espermatozoide con acrosoma intacto puede penetrar al ovocito ${ }^{(116)}$. En el caso de la integridad del DNA espermático, se ha demostrado su importancia en la fertilización y en las primeras etapas del desarrollo embrionario, siendo reconocida como un parámetro indicativo del potencial de fertilización del espermatozoide ${ }^{(117,118)}$. Diversos estudios han mostrado una correlación significativa entre la vitalidad ( $\mathrm{r}=0.19-0.40)$, la integridad del acrosoma $(\mathrm{r}=0.52)$ y la fragmentación del DNA ( $\mathrm{r}=-0.49)$, y la fertilidad en campo de toros ${ }^{(94,95,97,99)}$. En adición, cuando se combinaron varios parámetros (cinética espermática, vitalidad, fragmentación del DNA y morfología) en modelos obtenidos por regresión, la correlación con fertilidad aumentó a más del $90 \%{ }^{(12)}$. Aunque la mayoría de estas pruebas se realiza a través del uso de citometría de flujo, se han desarrollado nuevas generaciones de módulos del sistema CASA para la evaluación 
automática de la vitalidad, la integridad del acrosoma y la fragmentación del DNA ${ }^{(92)}$. Sin embargo, se han realizado pocos estudios en bovinos usando estos nuevos módulos. Por lo tanto, la motilidad y morfología se muestran como los módulos más importantes del sistema CASA en términos de uso.

Estos estudios muestran el gran potencial de los sistemas CASA para estimar la calidad del semen, estudiar la función espermática y predecir la fertilidad. Sin embargo, los parámetros proporcionados por el sistema CASA, también han mostrado que tienen limitaciones y no se pueden usar de forma aislada como predictores confiables de la habilidad de fertilización del espermatozoide. Además, los espermatozoides son células complejas que requieren un gran número de criterios a considerar para lograr la fertilización ${ }^{(119)}$, por lo que el uso de diversos parámetros proporcionados por el sistema CASA dentro de un modelo de regresión se presenta como la mejor opción para tratar de predecir la fertilidad de una muestra de semen. Sin embargo, no existe un consenso sobre cuáles parámetros de la funcionalidad espermática usar ${ }^{(99)}$, quizá debido a las diferencias encontradas entre grupos de trabajo respecto a los parámetros correlacionados con la fertilidad.

Actualmente, el análisis de espermatozoides a través de un sistema CASA se usa ampliamente dentro de los protocolos de control de calidad de los centros de procesamiento de semen, principalmente el módulo de motilidad. En dichos protocolos se establecen umbrales para ciertas variables como la motilidad total y progresiva; los eyaculados por debajo de estos umbrales suelen ser descartados antes o después de la congelación ${ }^{(99)}$.

En México, existen diversas asociaciones, instituciones y empresas relacionadas al ámbito pecuario que cuentan con sistemas CASA. Estos se han usado de forma regular principalmente en el control de calidad de dosis comerciales de semen de bovinos, ovinos y porcinos. Sin embargo, también se han realizado estudios de la cinética de espermatozoides post-criopreservación de carneros Pelibuey-Blackbelly ${ }^{(120)}$, del cerdo Pelón Mexicano ${ }^{(121)}$ y de borregos Merino de la isla Socorro ${ }^{(122)}$, así como evaluaciones de muestras de semen criopreservadas del borrego Chiapas $^{(123)}$ y del bovino criollo corriente de Tamaulipas ${ }^{(124)}$ que se encuentran resguardadas en el Centro Nacional de Recursos Genéticos del INIFAP (CNRG-INIFAP). Por otro lado, los sistemas CASA se han vuelto más atractivos como parte de la evaluación práctica de la calidad espermática de muestras de semen en muchas especies domésticas. Sin embargo, existen múltiples causas por las que una evaluación de semen por medio de un sistema CASA puede variar, por ejemplo el mantenimiento del sistema y equipo, el manejo de las muestras y la experiencia del técnico ${ }^{(89)}$. Por tal motivo, es de vital importancia corroborar la eficacia del análisis. Para asegurarse de que el sistema CASA trabaja de forma adecuada, es crucial la validación de técnicos, protocolos y equipo. En este sentido, el CNRG-INIFAP cuenta con un ensayo validado ante la entidad mexicana de acreditación denominado "Evaluación de semen de animales domésticos" el cual se realiza a 
través de un sistema CASA. Esto permite que las evaluaciones de semen realizadas con este sistema se lleven a cabo con estándares de alta calidad ${ }^{(125)}$.

Los sistemas CASA han evolucionado en los últimos años para convertirse en herramientas poderosas para la evaluación rápida y objetiva de la calidad y función espermática de muestras de semen de bovinos. Los sistemas CASA continuarán desarrollándose para realizar nuevas, repetibles y cada vez más precisas pruebas que permitan aportar a la mejora de la fertilidad en campo.

\section{Multiovulación y transferencia de embriones (MOET)}

Bajo este concepto se agrupan una serie de biotecnologías reproductivas que tiene como propósito aumentar la capacidad de reproducción por el lado materno y se utiliza como una herramienta de mejoramiento genético. Estas biotecnologías incluyen: la selección de donadores (hembras y machos) de alto mérito genético, la superovulación de las donadoras, la recolección y evaluación de los embriones, su transferencia a vacas receptoras o la criopreservación de los mismos. Esta técnica ha tenido su mayor desarrollo en el ganado bovino, sin embargo, es ampliamente aplicada en especies como equinos, ovinos, caprinos y cérvidos entre otros ${ }^{(126)}$. Además del propósito ya referido (el mejoramiento genético), la MOET también se ha utilizado con fines de conservación de Recursos Zoogenéticos, ya que de acuerdo con la $\mathrm{FAO}^{(127)}$, es una excelente opción para conservar la diversidad genética y es la forma más rápida de restaurar una población en riesgo, por tal motivo el INIFAP cuenta con el Centro Nacional de Recursos Genéticos, donde se han realizado trabajos con el fin de generar bancos de germoplasma de razas bovinas con diferentes estatus de riesgo ${ }^{(128)}$.

El primer nacimiento a partir de la transferencia de embriones en mamíferos se logró en 1890, con embriones de conejo ${ }^{(129)}$, y la primera transferencia quirúrgica con éxito en bovinos se logró en $1951^{(130)}$. El conjunto de biotecnologías que involucran la MOET se desarrolló entre 1940 y 1960, estableciendo las bases de la industria de la transferencia de embriones, la cual inició en 1970, como una herramienta para la introducción masiva de razas europeas continentales a norteamérica ${ }^{(131)}$. La actividad moderna de la MOET, es el resultado de los esfuerzos de dos grupos: a) los científicos, quienes inicialmente desarrollaron los procedimientos y técnicas de la transferencia de embriones, y b) los veterinarios de campo, quienes aplicaron esta tecnología de forma comercial haciéndola práctica y disponible para la industria del ganado bovino, y posteriormente para otras especies productivas ${ }^{(131)}$.

A inicios de 1970, en Norteamérica se establecieron los primeros centros de transferencia de embriones entre los cuales se encontraban "Alberta Livestock Transfer" (Alberta, Canadá), "Modern Ova Trends" (Ontario, Canadá), Colorado State University (Colorado, Estados 
Unidos), "Carnation Genetics" (California, Estados Unidos) y "Codding Embryological Science, Inc." (Oklahoma, Estados Unidos) ${ }^{(132)}$. En nuestro país, las primeras transferencias embrionarias (TE) en bovinos, se realizaron en 1978 por técnicos norteamericanos, pero se desconocen los resultados. En febrero de 1979 se inauguró en Ajuchitlán, Querétaro, la Clínica de Transferencia de Embriones, como parte del Centro Nacional de Reproducción Animal, dependiente del Instituto Nacional de Inseminación Artificial y Reproducción Animal (INIARA), de la entonces Secretaría de Agricultura y Recursos Hidráulicos (SARH). Ahí, en ese mismo año, nació la primera becerra holstein de $\mathrm{MOET}^{(132)}$. La primera cría cebú por TE nació en 1981 en la empresa Carnation de México ${ }^{(133)}$.

El Centro de Mejoramiento Genético y Transplante de Embriones (CEMEGEN), dependiente de la paraestatal Leche Industrializada Conasupo (LICONSA), inició sus actividades en noviembre de 1986, produciendo embriones de las razas Holstein Friesian, Suizo Pardo, Jersey, Simmental, Simbrah y F1 Holstein x Gyr lechero (Gyrholando) y Holstein x Guzerat. Se estimaba que, a partir de 1993, se producirían 20,000 embriones al año a partir de 2,200 donadoras. El centro dejó de funcionar en 1994, entre 1987 y 1993 tuvo una producción de casi 42,000 embriones. Además, se realizaron 18 cursos de capacitación en la técnica a alrededor de 300 profesionistas y se efectuaron trabajos para 23 tesis de nivel licenciatura y 4 de maestría. La mayoría de los embriones producidos fueron congelados y posteriormente transferidos en diversos estados de la República ${ }^{(134)}$. Para 1990, el Centro Nacional de Reproducción Animal se volvió parte de la Comisión Nacional para el Mejoramiento Genético y la Reproducción Animal (CONAMEGRA), constituida mediante un convenio entre la Secretaría y la Confederación Nacional Ganadera (CNG). Se hicieron varios trabajos de TE para ganaderos de diversas partes del país y se estableció con LICONSA un convenio para la comercialización, entre 1993 y 1994, de 1,343 embriones producidos en el CEMEGEN, al precio de $\$ 100.00$ por embrión, cantidad muy por debajo de su costo de producción. CONAMEGRA vendió ese material genético a 33 productores de 11 estados de la República Mexicana, sus propios técnicos descongelaron 447 embriones, los transfirieron y lograron obtener $51 \%$ de gestaciones ${ }^{(135)}$. En 1993, el INIFAP recibió la donación de 1,558 embriones de CEMEGEN, siendo estos embriones F1 y 3/4 Holstein x Cebú para los programas genéticos de sus campos experimentales en el trópico. Ese mismo año, al Colegio de Posgraduados se le donaron 800 embriones y 300 cabezas de ganado bovino.

En 1994, LICONSA finiquita el comodato con la UNAM, subasta el ganado, liquida al personal y devuelve a la UNAM sus instalaciones, poniendo con ello fin a la operación del CEMEGEN $^{(135)}$.

La recolecta y transferencia de embriones fue un proceso en un inicio harto complejo, pues tanto la colección de los embriones en la donadora como su posterior transferencia a hembras receptoras se hacía por métodos quirúrgicos y usando anestesia general, implicando un enorme esfuerzo de logística, pues las donadoras y receptoras tenían que ser preparadas para 
la cirugía al mismo tiempo ${ }^{(132)}$. En una primera instancia, se logró que las cirugías tanto a donantes como a receptoras se realizaran con anestesia local; posteriormente, se desarrollaron los procedimientos para la colección no quirúrgica de embriones y su transferencia a receptoras, lo que facilitó el uso más generalizado de la técnica ${ }^{(136)}$. Los resultados obtenidos empleando los métodos no quirúrgicos, poco a poco se aproximaron a los obtenidos con los quirúrgicos, razón por la cual estos últimos cayeron en desuso ${ }^{(131)}$.

En lo que respecta a la estimulación ovárica para inducir multiovulación, siempre ha existido una alta variabilidad en la respuesta superovulatoria, a pesar de esfuerzos por controlar las fuentes de variación, lo que constituye uno de los principales problemas que afectan la eficiencia y rentabilidad de la MOET a nivel comercial ${ }^{(137)}$. En un trabajo realizado con superovulaciones sucesivas en vacas cebú en el campo experimental "El Macho", INIFAP; donde se contemplaron las variables de época, dosis de FSH y edad, se concluyó que no se puede afirmar que la respuesta inicial de una vaca cebú a la superovulación sea un buen predictor de respuestas subsecuentes de la misma vaca ${ }^{(138)}$.

Aunque a la fecha hay considerables avances en cuanto al estudio de la fisiología ovárica, así como factores inherentes a la donadora, aún quedan aspectos por entender para generar protocolos más eficientes de estimulación ovárica ${ }^{(139)}$.

En sus inicios, la superovulación era inducida con eCG, sin embargo, pocos años después se descubrió que el extracto crudo de pituitaria (FSH con $20 \%$ de LH) generaba mejor respuesta superovulatoria que la $\mathrm{eCG}^{(140)}$. En la actualidad los extractos de pituitaria son ampliamente utilizados, pero existe una alta variabilidad en cuanto a la cantidad de LH en los extractos crudos, en cambio, los purificados tienen una menor variación en la cantidad de LH. Se han realizado múltiples estudios para evaluar la producción in vivo de embriones utilizando extractos crudos y purificados ${ }^{(131)}$. En uno realizado en 1995, en México, en el CEMEGEN, se encontró que el extracto crudo produjo más embriones que el purificado en bovinos productores de leche ${ }^{(141)}$. Por el contrario, en un estudio realizado en 2014, en el INIFAP, con bovinos productores de carne, el extracto purificado generó más embriones que el extracto crudo $^{(142)}$; esto puede deberse a que el metabolismo hepático de los bovinos productores de leche es más acelerado comparado con el de bovinos productores de carne ${ }^{(143)}$.

A pesar de los muchos esfuerzos realizados por incrementar la producción de embriones por vaca por año a través de aumentar la respuesta ovárica al tratamiento superovulatorio, se ha avanzado poco ${ }^{(131)}$. El uso de CIDR en combinación con BE y prostaglandinas, ha permitido el desarrollo de un protocolo denominado Reciclado Rápido de Donadoras. Este protocolo reduce casi a la mitad el intervalo entre superovulaciones (33 a 35 días) sin que decline la respuesta, tanto en número de embriones producidos como en su calidad, en superovulaciones sucesivas hasta por año y medio ${ }^{(131,142)}$, lo cual permite que casi se duplique la producción de embriones transferibles por donadora por año. 
La primera criopreservación exitosa de embriones fue reportada en murinos en $1972^{(144)}$. Un año después, se logró el nacimiento del primer becerro procedente de un blastocisto previamente criopreservado usando una solución $2 \mathrm{M}$ de dimetilsulfóxido y empleando una tasa de congelación y descongelación de $0.2{ }^{\circ} \mathrm{C} / \mathrm{min}$ y $36^{\circ} \mathrm{C} / \mathrm{min}$, respectivamente ${ }^{(145)}$. Los primeros becerros nacidos a partir de embriones criopreservados en México, provinieron de embriones congelados en Colorado, EUA y transferidos en Nayarit, México, en un campo experimental del INIFAP ${ }^{(146)}$.

Por más de 10 años el glicerol fue el crioprotector de elección para la criopreservación de embriones bovinos; sin embargo, en 1992 se anunció un sistema de criopreservación para transferencia directa con el uso de etilenglicol como crioprotector; esto tuvo un efecto rápido y positivo a nivel mundial en la industria de la transferencia de embriones hasta nuestros días ${ }^{(131)}$.

Según datos de la Asociación Americana de Transferencia de Embriones, en 2009 se tenía contabilizado que aproximadamente $99 \%$ de los embriones bovinos de razas cárnicas y $94 \%$ de embriones bovinos de razas lecheras fueron congelados en etilenglicol para transferencia directa ${ }^{(131)}$.

\section{Producción in vitro de embriones bovinos (PIV)}

La biotecnología de PIV tiene una variedad de aplicaciones en ciencia básica y aplicada; en primera instancia, ha soportado la producción de embriones usados para una amplia variedad de investigaciones, incluyendo el tratamiento de la infertilidad en humanos. Desde luego es una herramienta para aumentar la productividad de animales de granja al incrementar el potencial de reproducción de animales de mayor mérito genético y, también, juega un papel relevante en la conservación de recursos genéticos animales, sobre todo en aquéllos en peligro de extinción ${ }^{(147)}$.

Conocida genéricamente como FIV (fertilización in vitro) o PIV (producción in vitro) es una biotecnología reproductiva, que al igual que la MOET, está compuesta de varias biotecnologías como: la maduración in vitro de óvulos, la capacitación espermática, la fertilización in vitro propiamente dicha y el cultivo de cigotos y embriones hasta estadios pre-eclosión ( 7 a 8 d post-fertilización) ${ }^{(148)}$. La PIV consiste en recuperar óvulos u ovocitos de los folículos ováricos para ser madurados y fertilizados en condiciones de laboratorio; los cigotos resultantes se cultivan hasta estadios post-compactación (mórula o blastocisto), momento en el que se transfieren a una vaca receptora o se criopreservan para posterior transferencia. Los ovocitos pueden provenir de ovarios de rastro o bien de animales vivos, por medio de aspiración guiada por ultrasonido (OPU) o TVA ${ }^{(148)}$. 
Esta biotecnología data de los años 70, donde investigaciones y logros registrados en los temas de desarrollo de medios de cultivo, maduración de ovocitos, capacitación espermática y fertilización (ocurridos en esa década y la siguiente ${ }^{(126)}$ ) condujeron al nacimiento, en 1987, del primer becerro producido completamente in vitro ${ }^{(149)}$. Si bien esta biotecnología en un inicio estuvo orientada primordialmente a la investigación y se basó en ensayos realizados a partir de ovarios obtenidos en rastro, con la incorporación de la TVA (que hizo posible obtener ovocitos inmaduros de donadoras vivas) se vislumbró la aplicación comercial como una herramienta más prometedora que la MOET para la producción masiva de crías a partir de progenitores de alto mérito genético. Lo anterior se confirma al observar que, a nivel mundial, en tanto el número de embriones colectados in vivo y transferidos se ha mantenido estable en los últimos años, el número de embriones FIV transferidos ha tenido un promedio anual de crecimiento del $12 \%$ y, por vez primera, en 2017, el número de embriones viables producidos in vitro, superó al número de embriones transferibles colectados in vivo ${ }^{(150)}$; esa tendencia se ha mantenido hasta el reporte de la Sociedad Internacional de Tecnología de Embriones (IETS por sus siglas en inglés) de 2019, con datos de $2018^{(151)}$. En este mismo reporte, se deja constancia de que la inmensa mayoría de embriones FIV viables fueron obtenidos a partir de óvulos colectados por TVA (98.9\%), en contraste con los pocos embriones obtenidos a partir de ovarios de rastro $^{(151)}$. La razón de lo anterior es la incertidumbre que se tiene con los ovarios de rastro desde el punto de vista genético y sanitario de obtener germoplasma apropiado para la producción comercial. Se sabe que existe un importante número de laboratorios de investigación donde se producen embriones PIV viables que se desechan una vez que cumplen su función, pero estos datos no los registra el comité de estadísticas de la $\operatorname{IETS}^{(152)}$.

A nivel mundial, existen dos eventos que han operado como fuerzas motoras en la PIV: la biotecnología de semen sexado y la de evaluaciones genómicas. La primera porque gracias a la PIV es posible maximizar el uso de semen sexado, al poder fertilizar un importante número de ovocitos (100+) con una sola dosis de semen, y la segunda porque hace posible intensificar el poder de la selección, gracias a que permite acortar intervalos de generación (TVA en becerras, habilitando el uso de su germoplasma antes de la edad para servicio) y aumentar la capacidad de reproducción por el lado materno. Así, estas tres biotecnologías (PIV, semen sexado, evaluaciones genómicas) juegan un papel relevante en el mejoramiento genético y la industria ganadera bovina en general ${ }^{(152)}$.

La PIV tuvo una época de gran crecimiento a principios del presente siglo, sobre todo en Brasil, donde en 2009, $85 \%$ de los embriones disponibles provenían de producción in vitro, lo que era equivalente a un $50 \%$ de la producción mundial. El éxito de las empresas brasileñas incentivó su expansión a otros países de Latinoamérica, incluyendo México, donde se asentaron, trabajando de manera independiente o asociadas con empresas mexicanas $\mathrm{u}$ organizaciones de productores. Lo logrado en Brasil no se ha podido replicar en México porque no se tienen las ventajas competitivas que sí posee ese país sudamericano (razas, 
demanda, tamaño de las unidades de producción, disponibilidad de receptoras $)^{(148)}$. No obstante lo anterior, sigue habiendo actividad moderada de estas empresas y otras nacionales; así, en 2018, se reportó en México la transferencia de casi 28,000 embriones, casi todos provenientes de PIV y en contraste se transfirieron poco más de 4,000 embriones obtenidos in vivo ${ }^{(151)}$.

A pesar de que se ha generado un considerable volumen de investigación respecto a los principales componentes de esta biotecnología (desarrollo de medios de cultivo secuenciales, control de agentes potencialmente tóxicos, exclusión de componentes séricos, inclusión de aminoácidos, vitaminas, agentes quelantes y hormonas, entre otros) ${ }^{(153-156)}$, así como de investigación en los procesos de maduración y fertilización in vitro de ovocitos ${ }^{(152-157)}$, lo cierto es que no se ha podido rebasar el límite de 40 a $50 \%$ de blastocistos obtenidos a partir de los ovocitos fertilizados, valor no muy alejado del de 30 a $40 \%$ que se tenía hace 20 años. Ello ha inclinado la atención hacia la falta de homogeneidad en la fuente de ovocitos como la causa más probable de las limitadas tasas de éxito de la PIV ${ }^{(155,157,158)}$. Por ello es imperativo que, a la par de seguir promoviendo a la PIV-TVA (en combinación con otras biotecnologías como el uso de semen sexado y evaluaciones genómicas) como una valiosa herramienta productiva, se siga realizando investigación para la PIV en mayores cantidades con respecto a los óvulos que se ponen a madurar, más competentes en su desarrollo posttransferencia y con mayor tolerancia a la criopreservación.

Por la complejidad y altos requerimientos de infraestructura y equipo, así como de personal capacitado en esta biotecnología, la investigación en PIV en México ha sido incipiente. Sólo algunas universidades como la Universidad Nacional Autónoma de México, Universidad Autónoma Metropolitana, la Universidad Veracruzana, la Universidad Autónoma de Nuevo León, la Universidad Autónoma de Tamaulipas, el Colegio de Posgraduados y la Universidad Autónoma de Chihuahua; algunas organizaciones de productores y empresas ganaderas y el INIFAP han trabajado con algunos temas de investigación en PIV. A continuación, se citan algunos resultados obtenidos en investigaciones realizadas en México en temas relacionados con la PIV de bovino: sobre agentes y condiciones de cultivo para reducir la producción de especies reactivas de oxígeno (ROS) en el medio de cultivo, en un trabajo realizado en el INIFAP, se encontró que reduciendo la tensión de $\mathrm{O}_{2}$ al $2 \%$, se incrementó el número de células en los blastocistos y se redujo la producción de $\operatorname{ROS}^{(159)}$. En otro trabajo realizado también en el INIFAP, se utilizó una fitoalexina, el Pterostilbene, como agente antioxidante a una concentración de $0.33 \mu \mathrm{M}$, encontrándose que redujo la producción de ROS y la presencia de lípidos intracitoplasmáticos en embriones de 7 días ${ }^{(160)}$; esto último se presenta como una alternativa para mejorar la criopreservación de embriones PIV. En un trabajo colaborativo entre el INIFAP y la UANL, se evaluó el efecto de la adición de una proteína de choque térmico (HSP70) sobre el desarrollo de embriones bovinos producidos in vitro, encontrándose que la adición de HSP70 a los medios de cultivo tiene efectos favorables sobre el porcentaje de blastocistos y número de células ${ }^{(161)}$. Se evaluó, también en el INIFAP, un 
sistema para cultivo individual de embriones denominado "WOW", encontrándose que, aunque produce similar número de embriones comparado con el cultivo grupal en microgotas, en el sistema WOW se produce un mayor porcentaje de embriones de mejor calidad morfológica ${ }^{(162)}$. En otro trabajo realizado en la UNAM, se comparó la efectividad de dos dispositivos de vitrificación para criopreservar embriones bovinos. Se comprobó que el Cryotop ${ }^{\circledR}$ es un soporte de vitrificación más efectivo que el Open Pulled Straw ${ }^{\circledR}$, al resultar en mayor viabilidad post-vitrificación ${ }^{(163)}$. En otro trabajo realizado entre el Colegio de Posgraduados y la Universidad Veracruzana, se probó la alternativa de emplear medios de cultivo usados en el sistema FIV de humanos para cultivar embriones bovinos, encontrándose que se pueden producir blastocistos con resultados similares ${ }^{(164)}$. Cabe señalar que los medios de cultivo que se emplean en humanos son frecuentemente más fáciles de conseguir en el mercado nacional. En otro trabajo, realizado en la Universidad Autónoma de Chihuahua, se comprobó que la adición IGF-I agregado a diferentes tiempos del proceso de PIV no produjo un efecto benéfico sobre el porcentaje de blastocistos ${ }^{(165)}$.

El futuro de la PIV en bovinos enfrenta importantes retos que se deben resolver para asegurar su utilidad como herramienta productiva, y soporte para investigación en múltiples áreas del conocimiento. La evolución de los medios de cultivo para proveer condiciones cercanas a las fisiológicas a gametos y embriones ha sido una de las áreas con mayor avance ${ }^{(152)}$, pese a lo cual, hoy en día, se siguen teniendo dificultades para producir embriones similares a los obtenidos in vivo, lo que se manifiesta en bajas tasas de preñez a la transferencia, baja tolerancia a la criopreservación y alteraciones en el desarrollo fetal y placentario ${ }^{(157)}$. Los esfuerzos de investigación se han centrado en el desarrollo de medios de cultivo químicamente definidos ${ }^{(166)}$, uso de compuestos reguladores del nivel de oxidación ${ }^{(167)}$, uso de compuestos deslipificantes o reguladores del metabolismo de lípidos ${ }^{(160,168)}$ y mecanismos tales como el uso de medios secuenciales para remover la presencia de moléculas tóxicas para el embrión ${ }^{(169)}$. Así mismo, en el desarrollo de métodos de criopreservación más amigables con el embrión producido in vitro, como la vitrificación ${ }^{(170)}$. Por otra parte, con el desarrollo de biotecnologías como el trasplante nuclear embrionario (blastómeros en estadio de 16 células) y somático (células cumulares, fibroblastos, etc.) ${ }^{(171)}$, se percibía un futuro importante para la modificación genética de embriones con fines productivos, médicos y de investigación (estudios de función génica, xenotransplantes, producción de proteínas recombinantes, mejoramiento genético y producción de alimentos) ${ }^{(172)}$ y su eventual clonación; sin embargo, a pesar de haberse obtenido algunos resultados alentadores, la inserción aleatoria de los transgenes generó resultados altamente variables e impredecibles, haciendo inviable el uso de esta tecnología ${ }^{(173)}$. Actualmente, con el advenimiento de las tecnologías de edición de genes (CRISPR - Cas - 9), ya es posible realizar ediciones precisas de genes, incluso realizar reprogramaciones epigenéticas, lo que augura una época dorada en la modificación genética de animales de granja, con los fines antes mencionados, con el fuerte soporte de las biotecnologías de PIV ${ }^{(174)}$. Aún habrá impedimentos éticos y escollos legales que deberán resolverse. 


\section{Conclusiones}

A manera de reflexión final se puede decir que, aunque las instituciones de investigación en México y señaladamente el INIP-INIFAP han acompañado el desarrollo de las biotecnologías reproductivas en el mundo en las últimas cinco décadas, conforme han pasado los años, éstas han evolucionado de forma meteórica y ha sido cada vez más complicado mantener una base de investigación de frontera sólida que permita estar alineados con los desarrollos tecnológicos que van sucediendo. A pesar de que la información generada por instituciones mexicanas en temas actuales como la producción in vitro de embriones es modesta, la industria ganadera nacional está demandando la inmersión en estas tecnologías. Lo anterior debe empujar a las instituciones de investigación a generar componentes tecnológicos que permitan el uso eficiente de ésta y otras tecnologías bajo las condiciones locales.

\section{Literatura citada:}

1. Secretariat of the Convention on Biological Diversity. Handbook of the Convention on Biological Diversity Including its Cartagena Protocol on Biosafety, 3rd ed. Montreal, Canada; 2005.

2. Kiracofe GH. Uterine involution: Its role in regulating postpartum intervals. J Anim Sci 1980;51(Suppl 2):16-28.

3. Short RE, Bellow RA, Staigmiller RB, Berardinelli JG, Custer EE. Physiological mechanisms controlling anestrous and fertility in postpartum beef cattle. J Anim Sci 1990;68:799-816.

4. Wettemann RP, Lents CA, Ciccioli NH, White FJ, Rubio I. Nutritional and sucklingmediated anovulation in beef cows. J Anim Sci 2003;81(Suppl 2):E48-E59.

5. Montiel F, Ahuja C. Body condition and suckling as factors influencing the duration of postpartum anestrous in cattle: a review. Anim Reprod Sci 2005;85:1-26.

6. Lozano DRR, Asprón PMA, González PE, Vásquez PCG. Estacionalidad reproductiva de vacas Bos indicus en el trópico mexicano. Téc Pecu Méx 1987;25(2):192-205.

7. Lozano DF, Román PH, Castillo RH, González PE. Tratamiento del anestro posparto en vacas de ordeña en el trópico. Téc Pecu Méx 1984;46:19-24.

8. Zárate-Martínez JP, Ramírez-Godinez JA, Rodríguez-Almeida FA. Comportamiento reproductivo de vacas criollas con amamantamiento restringido y sincronización del estro. Agron Mesoam 2010;21(1):121-130. 
9. Wiltbank JN. Managing beef cows to get them pregnant. Texas Agricultural Experimental Station at Beeville, USA. 1972.

10. Wiltbank JN. Getting heifers pregnant. Memorias del Seminario Internacional de Ganadería Tropical. Producción de carne. SAG-Banco de México. 1976:175.

11. de los Santos VSG, Taboada SJJ, Montaño BM, González PE, Ruíz DR. Efecto de la lactación controlada y tratamientos con hormonas esteroides en la inducción y sincronización del estro en vacas encastadas de cebú. Téc Pecu Méx 1979;36:9-14.

12. Preston TR, Willis MB. Producción intensiva de carne. Primera ed. México: Editorial Diana; 1974.

13. Rodríguez ROL, Rodríguez RA, González PE, Ruiz DR. Comportamiento reproductivo de vacas productoras de carne sometidas a diversos tipos de amamantamiento. Téc Pecu Méx 1982;43:63-69.

14. Christian R, Casida L. The effects of progesterone in altering the oestrous cycle of the cow. J Anim Sci 1948;7:540.

15. Wiltbank JN, Kasson CW. Synchronization of estrus in cattle with an oral progestational agent and an injection of an estrogen. J Anim Sci 1968;27:113.

16. Rowson LEA, Tervit HR, Brand A. The use of prostaglandins for synchronization of oestrus in cattle. J Reprod Fert 1972;29(1):145.

17. Nellor JE, Cole HH. The hormonal control of estrus and ovulation in the beef heifer. $\mathrm{J}$ Anim Sci 1956;15:650-661.

18. Hansel W, Malven PV, Black DL. Estrous cycle regulation in the bovine. J Anim Sci 1961;20:621-625.

19. Zimbelman RG, Lauderdale JW, Sokolowski JH, Schalk TG. Safety and pharmacologic evaluations of melengestrol acetate in cattle and other animals. A review. J Am Vet Med Assoc 1970;157:1528-1536.

20. Gonzalez PE, Wiltbank JN, Niswender GD. Puberty in beef heifers. I. The interrelationship between pituitary, hypothalamic and ovarian hormones. J Anim Sci 1975;40(6):1091-1104.

21. González PE, Ruíz DR, Wiltbank JN. Inducción y sincronización del estro en vaquillas prepúberes mediante la administración de estrógenos y un progestágeno. Téc Pecu Méx 1975;28:17-23. 
22. de los Santos VSG, González PE. Combinación de cipionato de estradiol, progesterona e implantes del progestágeno SC21009 para la resolución del anestro en ganado bovino productor de carne. Téc Pecu Méx 1976;31:55-62.

23. Menéndez TM, Robles BC, González PE. Inducción del estro con esteroides en vacas cebú lactantes. Téc Pecu Méx 1977;33:15-19.

24. Menéndez TM, Robles BC, González PE. Sincronización del estro en vacas cebú con y sin suplemento de melaza + urea. Téc Pecu Méx 1977;33:9-14.

25. Rodríguez RA, Casillas TO, González PE. Empleo de acetato de melengestrol, valerato de estradiol y progesterona para el control del estro en bovinos suizo pardo x cebú. Téc Pecu Méx 1977;32:41-45.

26. Rodríguez RA, Rodríguez ROL, González PE, Ruíz DR. Inseminación a horarios predeterminados en vaquillas sincronizadas con implantes de SC21009. Téc Pecu Méx 1979;36:53-58.

27. Menéndez TM, Ruíz DR, González PE. Establecimiento de épocas cortas de inseminación artificial mediante el uso de la sincronización del estro. Téc Pecu Méx 1979;36:15-20.

28. Lauderdale JW. Effects of PGF $2 \alpha$ on pregnancy and estrous cycle of cattle. J Anim Sci 1972;35(1):246.

29. King GJ, Robertson HA. A two injection schedule with prostaglandin F2 $\alpha$ for the regulation of the ovulatory cycle of cattle. Theriogenology 1974;1:123-128.

30. Rodríguez ROL, Rodríguez RA, González PE. Diferentes horarios de inseminación artificial en vaquillas productoras de carne sincronizadas con prostaglandinas. Téc Pecu Méx 1982;43:55-62.

31. Heersche G, Kiracofe GH, DeBenedetti RC, Wen S, McKee RM. Synchronization of estrus in beef heifers with a norgestomet implant and prostaglandin $\mathrm{F} 2 \alpha$. Theriogenology 1979;11:197-208.

32. Twagiramungu H, Guilbault LA, Proulx J, Dufour JJ. Effect of Synchromate-B and prostaglandin F2 $\alpha$ on estrus synchronization and fertility in beef cattle. Can J Anim Sci 1992;72:31-39.

33. Kastelic JP, Olson WO, Martinez M, Cook RB, Mapletoft RJ. Synchronization of estrus in beef cattle with norgestomet and estradiol valerate. Can Vet J 1999;40:173-178. 
34. Stevenson JS, Thompson KE, Forbes WE, Lamb GC, Grieger DM, Corah LR. Synchronizing estrus and(or) ovulation in beef cows after combinations of GnRH, norgestomet and prostaglandin $\mathrm{F}_{2} \alpha$ with or without timed insemination. J Anim Sci 2000;78:1747-1758.

35. Faustino CR, Rosete FJV, Ríos UA, Vega MVE. Inducción del estro con un implante de norgestomet y valerato de estradiol, complementado con gonadotropina coriónica equina en vacas cárnicas en una época de empadre [resumen]. Reunión Nacional de Investigación Pecuaria. Mérida, Yucatán. 2008:262.

36. Koppel RET, Rodríguez ROL. Sincronización del estro con progestágenos e inseminación a tiempo predeterminado en vaquillas cebú bajo condiciones de trópico. Téc Pecu Méx 1989;27(2):53-61.

37. Patterson DJ, Cojima FN, Smith MF. A review of methods to synchronize estrus in replacement beef heifers and postpartum cows. J Anim Sci 2003;81(Suppl 2):E166E177.

38. De La Torre SJF, Galavíz RI, Estrada MA, Villagómez AE, Ortíz MEP. Evaluación de un esquema de inducción/sincronización del estro en vacas angus y limousin con cría al pie [resumen]. Reunión Nacional de Investigación Pecuaria. Saltillo, Coahuila. 2009:76.

39. Chaga LE, Zárate MJP, Rosas PJ, Alpírez MF, Domínguez MB. Niveles séricos de progesterona e inseminación artificial a tiempo fijo y a 12 horas posteriores al estro en vaquillas cruzadas utilizando los protocolos CO-SYNCH-CIDR y CRESTAR plus. XXII Reunión Científica-Tecnológica Forestal y Agropecuaria Veracruz 2009. Úrsulo Galván, Veracruz. 2009:478-487.

40. Vera AHR, Villa GA, Jiménez SH, Álvarez GH, De La Torre SJF, Gutiérrez ACG, et al. Eficiencia reproductiva de los bovinos en el trópico. En: editores Rodríguez RO, González PE, Dávalos FJL. Estado del arte sobre investigación e innovación tecnológica en ganadería bovina tropical. Primera ed. Ciudad de México, México: REDGATROCONACYT; 2015:153-192.

41. Rodríguez ROL, Rodríguez RA, Zambrano GR, González PE. Comportamiento reproductivo de vacas con aumentos de peso controlados antes y después del parto. Téc Pecu Méx 1979;36:40-46.

42. Ciccioli NH, Wettemann RP, Spicer LJ, Lents CA, White FJ, Keisler DH. Influence of body condition at calving and postpartum nutrition on endocrine function and reproductive performance of primiparous beef cows. J Anim Sci 2003;81(12):310731020. 
43. Guzmán SA, González PE, Garcés YP, Rosete FJV, Calderón RC, Murcia C, et al. Reducción en las concentraciones séricas de insulina e IGF-1 pero no leptina, se asocia a una reducción en la respuesta a un programa de inducción de estros en vacas de carne amamantando [resumen]. Reunión Nacional de Investigación Pecuaria. Saltillo, Coahuila. 2009:50.

44. Guzmán A, González PE, Garcés YP, Rosete FJV, Calderón RC, Murcia C, et al. Reduced response to an estrous induction program in postpartum beef cows treated with zilpaterol and gaining body weight. Anim Reprod Sci 2012;130:1-8.

45. Rosales TAM, López CZB, Hernández CCG, Rosete FJV, Mendoza GD, Guzmán A. Short-term dietary concentrate supplementation during estrus synchronization treatment in beef cows increased IGF-1 serum concentration but did not affect the reproductive response. Trop Anim Health Prod 2017;49(1):221-226.

46. Mead E, Maguire JJ, Kuc RE, Davenport AP. Kisspeptins: a multifunctional peptide system with a role in reproduction, cancer and the cardiovascular system. British J Pharmacol 2007;151:1143-1153.

47. Navarro VM, Tena-Sempere M. Neuroendocrine control by kisspeptins: role in metabolic regulation of fertility. Nat Rev Endocrinol 2012;8:40-53.

48. Kadokawa H, Matsui M, Hayashi K, Matsunaga N, Kawashima C, Shimizu T, et al. Peripheral administration of kisspeptin-10 increases plasma concentrations of $\mathrm{GH}$ as well as LH in prepubertal Holstein heifers. J Endocrinol 2008;196:331-334.

49. Ezzat AA, Saito H, Sawada T, Yaegashi T, Yamashita T, Hirata TI, et al. Characteristics of the stimulatory effect of Kisspeptin-10 on the secretion of luteinizing hormone, follicle-stimulating hormone and growth hormone in prepubertal male and female cattle. J Reprod Dev 2009;55:650-654.

50. Alamilla RM, Calderón RRC, Rosete FJV, Rodríguez HK, Vera AHR, Arreguín AJA, et $a l$. Kisspeptina en becerras prepúberes: I. Influencia de la edad en la respuesta de LH, FSH y GH a kisspeptina-10 y su asociación con IGF-I, leptina y estradiol. Rev Mex Cienc Pecu 2007;8(4):375-385.

51. Santos ER, Calderón RRC, Rosete FVJ, Perera MG, Murcia MC, Villagómez AME, et $a l$. Evaluación de la sensibilidad del eje gonadotrópico a dosis bajas de kisspeptina (KISS-10) en becerras prepúberes [resumen]. Reunión Nacional de Investigación Pecuaria. Querétaro, Querétaro. 2012:125. 
52. Villa GA, Santos ER, Rosete FJV, Calderón RRC, Perera MG, Arreguín AJA, et al. Kisspeptina en becerras prepúberes: 2. Respuesta de LH, FSH y GH a distintas dosis de kisspeptina-10 y su asociación con IGF-I y leptina circulantes. Rev Mex Cienc Pecu 2018;9(4):719-737.

53. Santos ER, Calderón RRC, Vera AHR, Perea MG, Arreguín AJA, Nett TM, et al. Hormona luteinizante y actividad ovárica en respuesta a kisspeptina-10 y su asociación con IGF-1 y leptina en becerras prepúberes. Rev Mex Cienc Pecu 2014;5(2):181-200.

54. Rosete FJV, Hernández LB, Santos ER, Gómez CBM, Perera MG, Calderón RRC, et al. Respuesta de hormona luteinizante a aplicaciones repetidas de kisspeptina-10 en vacas en anestro posparto [resumen]. Reunión Nacional de Investigación Pecuaria. Toluca, Estado de México. 2015:61-63.

55. Fragoso IA, Rosete FJV, Ríos UA, Santos ER. Efecto de la kispeptina-10 en la ovulación y gestación en vacas tratadas con sincronización estral [resumen]. II Congreso Internacional de Agroecosistemas Tropicales. Yucatán. 2020:70.

56. Spallanzani L. Dissertations relative to the natural history of animals and vegetables. Trans. By T. Beddoes. London: J. Murray; 1784;2:195-199.

57. Phillips EJ, Lardy HA. A yolk-buffer pabulum for the preservation of bull semen. J Dairy Sci 1940;(23):399-404.

58. Salisbury GW, Fuller HK, Willett EL. Preservation of bovine spermatozoa in yolk-citrate diluents and field results from its use. J Dairy Sci 1941;24:905-910.

59. Polge C, Smith AU, Parkes AS. Revival of spermatozoa after vitrification and dehydration at low temperatures. Nature 1949;164:166.

60. Ombelet W, Van Robays J. Artificial insemination history: hurdles and milestones. Facts Views Vis Obgyn 2015;7(2):137-143.

61. Polge C, Rowson LEA. Results with bull semen stored at $-79^{\circ} \mathrm{C}$. Vet Rec $1952 ; 64: 851-$ 853.

62. Manjunath P, Bergeron A, Lefebvre J, Fan J. Seminal plasma proteins: functions and interaction with protective agents during semen preservation. Soc Reprod Fertil Suppl 2007;65:217-228.

63. Lenz RW, Zhang HM, Oyarzo JN, Bellin ME, Ax RL. Bovine fertility-associated antigen (FAA) and a recombinant segment of FAA improve sperm function. Biol Reprod 1999;62:137-138. 
64. Alvarez GH, Kjelland ME, Moreno JF, Welsh TH Jr, Randel RD, Lammoglia MA, et al. Gamete therapeutics: recombinant protein adsorption by sperm for increasing fertility via artificial insemination. PLoS One 2013;8(6):e65083.

65. Seidel Jr GE, Garner DL. Current status of sexing mammalian spermatozoa. Reproduction 2002;124:733-743.

66. Garner DL. Sex-sorting mammalian sperm: Concept to application in Animals. J Adrol 2001;22(4):519-26.

67. Garner DL, Seidel Jr GE. Past, present and future perspectives on sexing sperm. Can J Anim Sci 2003;83:375-384.

68. Seidel Jr GE. Sperm sexing technology. The transition to commercial application. An introduction to the symposium "Update on sexing mammalian sperm". Theriogenology 2009;71:1-3.

69. Garner DL, Seidel Jr GE. History of commercializing sexed semen for cattle. Theriogenology 2008;69:886-895.

70. Oses MV, Teruel MT, Cabodevila JA. Utilización de semen bovino sexado en inseminación artificial, transferencia embrionaria y fertilización in vitro. Red Vet 2009;20:138-145.

71. Seidel Jr GE, Allen CH, Johnson LA, Holland MD, Brink Z, Welch GR. Uterine horn insemination of heifers with very low numbers of nonfrozen and sexed sperm. Theriogenology 1997;48:1255-1264.

72. Schenk JL, Suh TK, Cran DG, Seidel GE Jr. Cryopreservation of flow-sorted bovine spermatozoa. Theriogenology 1999;52(8):1375-1391.

73. STgenetics. https://www.stgen.com Accessed 15 Sep, 2020.

74. Johnson LA, Welch GR. Sex preselection: high speed flow cytometric sorting of X and Y sperm for maximum efficiency. Theriogenology 1999;52:1323-1341.

75. Vishwanath R, Moreno JF. Review: Semen sexing - current state of the art with emphasis on bovine species. Animal 2018;12(Suppl 1):1-12.

76. González MC, Lenz RW, Gilligan TB, Evans KM, Gongora CE, Moreno JF, et al. SexedULTRA $^{\mathrm{TM}}$, a new method of processing sex sorted bovine sperm improves postthaw sperm quality and in vitro fertility. Reprod Fert Develop 2017;29(1):204. 
77. González MC, Góngora CE, Guilligan TB, Evans KM, Moreno JF, Vishwanath R. In Vitro sperm quality and DNA integrity of SexedULTRATM sex sorted sperm compared to non sorted bovine sperm. Theriogenology 2018;114:40-45.

78. Vishwanath R. 2014. SexedULTRA - raising the fertility bar of sexed sorted semen. In Proc 25th Tech Conf Artif Insem Reprod. National Association of Artificial Breeders, September 2014, Wisconsin, USA, 57-61.

79. Lenz RW, González MC, Gilligan TB, DeJarnette JM, Utt MD, Helser LA, et al. SexedULTRA ${ }^{\mathrm{TM}}$, a new method of processing sex sorted bovine sperm improves conception rates. Reprod Fert Develop 2017;29(1):203-204.

80. Crites BR, R Vishwanath, AM Arnett, PJ Bridges, WR Burris, KR McLeod, et al. Conception risk of beef cattle after fixed-time artificial insemination using either SexedUltra ${ }^{\mathrm{TM}} 4 \mathrm{M}$ sex-sorted semen or conventional semen. Theriogenology 2018;118:126-129.

81. Thomas JM, Locke JWC, Bonacker RC, Knickmeyer ER, Wilson DJ, Vishwanath R, et al. Evaluation of SexedULTRA 4MTM sex sorted semen in timed artificial insemination programs for mature beef cows. Theriogenology 2019;123:100-107.

82. Pérez EJI. Comparación de la frecuencia de nacimientos de hembras con el método de inseminación artificial con semen sexado y no sexado en vaquillas holstein-friesian [tesis licenciatura]. México: Universidad Nacional Autónoma de México; 2007.

83. De La Torre SJF, Hernández VR, Padilla RFJ, Reynoso CO, Maciel RMG. Uso de semen sexado en vaquillas holstein en el Estado de Jalisco [resumen]. XLIV Reunión Nacional de Investigación Pecuaria. Yucatán, México. 2008:84.

84. Callejas SJA. Evaluación del uso de semen sexado en vaquillas Holstein de reemplazo [tesis maestría]. Baja California, México: Universidad Autónoma de Baja California; 2013.

85. Villaseñor GF, de la Torre SJF, Estrada CE, Martínez VG, Coronado BH. Efecto de la presencia de mastitis en el posparto temprano sobre la fertilidad en vacas del sistema familiar inseminadas con semen sexado [resumen]. XLVIII Reunión Anual de Investigación Pecuaria. Querétaro, México. 2012:132.

86. Villaseñor GF, De La Torre SJF, Hernández VR, Martínez VG, Estrada CE. Prevalencia de abortos y distocias en vaquillas holstein inseminadas con semen sexado en el Estado de Jalisco. XLVI Reunión Nacional de Investigación Pecuaria [resumen]. Campeche, México. 2010:154. 
87. Vincent P, Underwood SL, Dolbec C, Bouchard N, Kroetsch T, Blondin P. Bovine semen quality control in artificial insemination centers. Anim Reprod 2018;9(3):153-165.

88. García MV, de Paz P, Martinez PF, Alvarez M, Gomes AS, Bernardo J, et al. DNA fragmentation assessment by flow cytometry and Sperm-Bos-Halomax (bright-field microscopy and fluorescence microscopy) in bull sperm. Int J Androl 2007;30(2):88-98.

89. Amann RP, Waberski D. Computer-assisted sperm analysis (CASA): Capabilities and potential developments. Theriogenology 2014;81:5-17.

90. Utt MD. Prediction of bull fertility. Anim Reprod Sci 2016;169:37-44.

91. Mortimer ST. CASA—practical aspects. J Androl 2000;21(4):515-524.

92. van der Horst G, Maree L, du Plessis SS. Current perspectives of CASA applications in diverse mammalian spermatozoa. Reprod Fert Develop 2018;30(6):875-888.

93. Lu JC, Huang YF, Lü NQ. Computer-aided sperm analysis: past, present and future. Andrologia 2014;46(4):329-338.

94. Muiño R, Tamargo C, Hidalgo CO, Peña AI. Identification of sperm subpopulations with defined motility characteristics in ejaculates from Holstein bulls: effects of cryopreservation and between-bull variation. Anim Reprod Sci 2008;109:27-39.

95. Muiño R, Peña AI, Rodríguez A, Tamargo C, Hidalgo CO. Effects of cryopreservation on the motile sperm subpopulations in semen from Asturiana de los Valles bulls. Theriogenology 2009;72:860-868.

96. Küçük N, Lopes JS, Soriano-Úbeda C, Hidalgo CO, Romar R, Gadea J. Effect of oviductal fluid on bull sperm functionality and fertility under non-capacitating and capacitating incubation conditions. Theriogenology 2020;158:406-415.

97. Correa JR, Pace MM, Zavos PM. Relationships among frozen-thawed sperm characteristics assessed via the routine semen analysis, sperm functional tests and fertility of bulls in an artificial insemination program. Theriogenology 1997;48(5):721731.

98. Gliozzi TM, Turri F, Manes S, Cassinelli C, Pizzi F. The combination of kinetic and flow cytometric semen parameters as a tool to predict fertility in cryopreserved bull semen. Animal 2017;11:197-1982.

99. Januskauskas A, Johannisson A, Rodriguez-Martinez H. Subtle membrane changes in cryopreserved bull semen in relation with sperm viability, chromatin structure, and field fertility. Theriogenology 2003;60:743-758. 
100. Karoui S, Díaz C, González MC, Amenabar ME, Serrano M, Ugarte E, et al. Is sperm DNA fragmentation a good marker for field AI bull fertility? J Anim Sci 2012;90:24372449.

101. Gillan L, Kroetsch T, Maxwell WC, Evans G. Assessment of in vitro sperm characteristics in relation to fertility in dairy bulls. Anim Reprod Sci 2008;103:201-214.

102. Morrell JM, Nongbua T, Valeanu S, Verde IL, Lundstedt-Enkel K, Edman A, et al. Sperm quality variables as indicators of bull fertility may be breed dependent. Anim Reprod Sci 2017;185:42-52.

103. Farrell PB, Presicce GA, Brockett CC, Foote RH. Quantification of bull sperm characteristics measured by computer-assisted sperm analysis (CASA) and the relationship to fertility. Theriogenology 1998;49(4):871-879.

104. van der Horst G. Computer Aided Sperm Analysis (CASA) in domestic animals: Current status, three D tracking and flagellar analysis. Anim Reprod Sci 2020;220:106350.

105. Valverde A, Madrigal-Valverde M. Computer-assisted semen analysis systems in animal reproduction. Agron Mesoam 2018;29:469-484.

106. Menkveld R, Holleboom CA, Rhemrev JP. Measurement and significance of sperm morphology. Asian J Androl 2011;13:59-68.

107. Rodríguez-Martínez H. State of the art in farm animal sperm evaluation. Reprod Fertil Dev 2006;19:91-101.

108. Al-Makhzoomi A, Lundeheim N, Haard M, Rodríguez MH. Sperm morphology and fertility of progeny-tested AI dairy bulls in Sweden. Theriogenology 2008;70:682-691.

109. van der Horst G, du Plessis SS. Not just the marriage of Figaro: but the marriage of WHO/ESHRE semen analysis criteria with sperm functionality. Adv Androl Online 2017;4:6-21.

110. Yániz JL, Soler C, Santolaria P. Computer assisted sperm morphometry in mammals: a review. Anim Reprod Sci 2015;156:1-12.

111. van der Horst G, Skosana B, Legendre A, Oyeyipo P, Du Plessis SS. Cut-off values for normal sperm morphology and toxicology for automated analysis of rat sperm morphology and morphometry. Biotech Histochem 2018;93:49-58.

112. Gil MC, García HM, Barón FJ, Aparicio IM, Santos, AJ, García MLJ. Morphometry of porcine spermatozoa and its functional significance in relation with the motility parameters in fresh semen. Theriogenology 2009;71:254-263. 
113. Gravance CG, Casey ME, Casey PJ. Pre-freeze bull sperm head morphometry related to post-thaw fertility. Anim Reprod Sci 2009;114:81-88.

114. Valverde A, Aremán H, Sancho M, Contell J, Yániz J, Fernández A, et al. Morphometry and subpopulation structure of Holstein bull spermatozoa: variations in ejaculates and cryopreservation straws. Asian J Androl 2016;18:851-857.

115. Garner DL, Thomas CA, Joerg HW, Mel Dejarnette J, Marshall CE. Fluorometric assessments of mitochondrial function and viability in cryopreserved bovine spermatozoa. Biol Reprod 1997;57:1401-1406.

116. Lange CA, Meucci A, Cremonesi F. Fluorescent multiple staining and CASA system to assess boar sperm viability and membranes integrity in short and long-term extenders. Open Vet J 2013;3:21-35.

117. Agarwal A, Said TM. Role of sperm chromatin abnormalities and DNA damage in male infertility. Hum Reprod Update 2003;9:331-345.

118. Gil-Villa AM, Cardona MW, Agarwal A, Sharma R, Cadavid Á. Assessment of sperm factors possibly involved in early recurrent pregnancy loss. Fertil Steril 2010;94:14651472.

119. Gillan L, Evans G, Maxwell WMC. Flow cytometric evaluation of sperm parameters in relation to fertility potential. Theriogenology 2005;63:445-457.

120. Gómez VJC, Cuicas HR, Jáuregui PI, Gutiérrez SI, Ulloa AR, Urban DD, et al. Determinación de la congelabilidad de carneros de pelo (Pelibuey-Blackbelly) de acuerdo con la viabilidad y cinética espermática. Spermova 2020;10:26-31.

121. Herrera JAH. Efecto del tipo de azúcar utilizado en el diluyente sobre la criopreservación del semen de cerdo pelón mexicano [tesis doctoral]. Yucatán, México: Tecnológico Nacional de México; 2017.

122. Barragán SAL. Evaluación de cuatro criodiluyentes sobre algunas variables de respuesta seminal pre y post-descongelamiento en borregos Merino isla Socorro, con fines de preservación [tesis maestría]. Jalisco, México: Universidad de Guadalajara; 2018.

123. Urbán DD, Méndez-Gómez AC, Álvarez GH, Pérez RS, De La Torre SJF, Pedraza VJP. Conservación ex situ, in vitro y calidad seminal del borrego Chiapas. Rev Mex Agroecosistemas 2016; 3(Suppl 2):112-115.

124. Pérez RS, Urbán DD, Álvarez GH, De La Torre SJF, Palacios GMA. Conservación ex situ, in vitro y calidad seminal del bovino criollo corriente de Tamaulipas. Rev Mex Agroecosistemas 2016;3(Suppl 2):116-118. 
125. Álvarez GH, Urban DD, Pérez RS, De La Torre SJF. Validación del ensayo de evaluación de semen bovino mediante un sistema "CASA" (Computer Assited Sperm Analyzer). VII Congreso Virtual Iberoamericano sobre la Gestión de Calidad en Laboratorios IBEROLAB. Madrid, España. 2014:259-260.

126. Moore SG, Hasler JF. A 100-Year Review: Reproductive technologies in dairy science. J Dairy Sci 2017;100(12):10314-10331.

127. FAO. Cryoconservation of animal genetic resources. FAO: Rome. Animal Production and Health Guidelines No. 12. 2012..

128. Villaseñor GF, De La Torre SJF, Martínez VG, Álvarez GH, Pérez RS, Palacios FJA, et al. Caracterización de la respuesta ovárica a la superovulación en bovino criollo coreño utilizando dosis reducidas de FSH. Rev Mex Cien Pecu 2017;8(3):225-232.

129. Heape W. Preliminary note on the transplantation and growth of mammalian ova within a uterine foster-mother. Proc Roy Soc London B 1890;48:457-9.

130. Willett EL, Black WG, Casida LE, Stone WH, Buckner PG. Successful transplantation of a fertilized bovine ovum. Science 1951;113:247.

131. Hasler JF. Forty years of embryo transfer in cattle: a review focusing on the Journal Theriogenology, the growth of the industry in North America, and personal reminiscences. Theriogenology 2014;81(1):152-69.

132. Cerda AA. Crecen saludables en México los primeros becerros de probeta. El sol del campo 22 de abril 1980:1-4.

133. Asprón PMA. Evolución histórica de la transferencia de embriones. Revista Cebú 1989;15(3):47-54.

134. Sánchez AA, Ramírez CJ. Apoyos de LICONSA a los ganaderos lecheros en diferentes regiones de México. En: Martínez BE, et al, coord. Dinámica del sistema lechero mexicano en el marco regional y global. México: Ed. Plaza y Valdés; 1999:270-291.

135. México Holstein. CONAMEGRA tutela el mejoramiento genético de la ganadería. 1994;25:29-31.

136. Elsden RP, Hasler JF, Seidel GE Jr. Non-surgical recovery of bovine eggs. Theriogenology 1976;6(5):523-32.

137. Córdoba SLA. Superovulación inducida en ganado bovino. Téc Pecu Méx 1988;26(1):109-119. 
138. De La Torre SJF, Castro LMA, González PE, Reynoso CO. Respuesta de vacas cebú a superovulaciones sucesivas con FSH. Téc Pecu Méx 1992;30(3):223-231.

139. Mikkola M, Hasler JF, Taponen J. Factors affecting embryo production in superovulated Bos taurus cattle. Reprod Fertil Dev 2019;32(2):104-124.

140. Bó GA, Mapletoft RJ. Historical perspectives and recent research on superovulation in cattle. Theriogenology 2014;81(1):38-48.

141. Martínez BS, Sánchez AA, Anta JE, Berruecos VJM, Valencia MJ. Valoración de dos hormonas folículo estimulantes comerciales usadas en la superovulación de vacas en lactación y vaquillas en ganado lechero. Téc Pecu Méx 1995;33(1):34-38.

142. Polanco SR. Efecto de dos preparaciones de FSH-LH al inducir multiovulación usando reciclado rápido y tradicional en donadoras Brangus rojo [tesis maestría]. Xalisco, Nayarit, México: Universidad Autónoma de Nayarit; 2014

143. Hart CG, Voelz BE, Brockus KE, Lemley CO. Hepatic steroid inactivating enzymes, hepatic portal blood flow and corpus luteum blood perfusion in cattle. Reprod Domest Anim 2018;53(3):751-758.

144. Whittingham DG, Leibo SP, Mazur P. Survival of mouse embryos, frozen to $-196^{\circ} \mathrm{C}$ and $-289^{\circ} \mathrm{C}$. Science $1972 ; 178: 411-414$.

145. Wilmut I, Rowson LEA. Experiments on the low-temperature preservation of cow embryos. Vet Rec 1973;92:686-690.

146. de los Santos-Valadez S, Tervit HR, Elsden RP, Seidel GE. Transport of frozen cattle embryos from U.S.A. to Mexico. Theriogenology 1981;15(1):123.

147. Bavister BD. Early history of in vitro fertilization. Reproduction 2002;124:181-196.

148. Vera AHR, Santos ER, Hernández MJH, Gutiérrez ACG, de la Torre SJF, Álvarez GH, et al. Eficiencia reproductiva de los bovinos en el trópico. En: Estado del arte sobre investigación e innovación tecnológica en ganadería bovina tropical. $2^{\mathrm{a}}$ ed. Ciudad de México, México: Red de investigación e innovación tecnológica para la ganadería bovina tropical. CONACYT; 2018.

149. Lu KH, Gordon I, Chen HB, McGovern H. In vitro culture of early bovine embryos derived from in vitro fertilization of follicular oocytes matured in vitro. Proc. Third Meet. Eur. Embryo Transf. Assoc. Lyon, France; 1987.

150. Viana JHM. 2017 Statistics of embryo production and transfer in domestic farm animals: Is it a turning point? In 2017 more in vitro-produced than in vivo-derived embryos were transferred worldwide. Embryo Transfer Newsletter 2018;36(3):8-25. 
151. Viana JHM. 2018 Statistics of embryo production and transfer in domestic farm animals, embryo industry on a new level: over one million embryos produced in vitro IETS Data Retrieval Committee. Embryo Technology Newsletter 2019;36(4).

152. Ferré LB, Kjelland, ME, Strøbech LB, Hyttel P, Mermillod P, Ross PJ. Review: Recent advances in bovine in vitro embryo production: reproductive biotechnology history and methods. Animal 2020;14:991-1004.

153. De La Torre SJF, Gardner D, Preis K, Gibbons, J, Seidel, GE. Metabolic regulation of in-vitro-produced bovine embryos. II. Effects of phenazine ethosulfate, sodium azide and 2,4-dinitrophenol during post-compaction development on glucose metabolism and lipid accumulation. Reprod Fert Develop 2006;8:597-607.

154. Lane M, Gardner D. Embryo culture medium: which is the best?. Best Pract Res Clin Obstet Gynaecol 2007;21(1):83-100.

155. Sanches BV, Zangirolamo AF, Seneda MM. Intensive use of IVF by large-scale dairy programs. Anim Reprod 2019;16(3):394-401.

156. Ferré LB, Kjelland ME, Taiyeb AM, Campos CF, Ross PJ. Recent progress in bovine in vitro-derived embryo cryotolerance: Impact of in vitro culture systems, advances in cryopreservation and future considerations. Reprod Dom Anim 2020;55:659-676.

157. Patel O, Bettegowda A, Ireland J, Coussens P, Lonergan P, Smith G. Functional genomics studies of oocyte competence: evidence that reduced transcript abundance for follistatin is associated with poor developmental competence of bovine oocytes. Reproduction 2007;133(1):95-148.

158. Sirard MA. 40 years of bovine IVF in the new genomic selection context. Reproduction 2018;156:R1-R7.

159. Delgado TGA. Efecto de diferentes niveles de oxígeno en la atmósfera de cultivo y la adición de un antioxidante comercial en el desarrollo de embriones bovinos producidos in vitro [tesis maestría]. Nayarit, México: Universidad Autónoma de Nayarit; 2013.

160. Sosa F, Romo S, Kjelland M, Álvarez GH, Pérez RS, Urbán DD, et al. Effect of pterostilbene on development, equatorial lipid accumulation and reactive oxygen species production of in vitro-produced bovine embryos. Reprod Dom Anim 2020;55:1-11.

161. Garza AAJ, Pérez RS, Urbán DD, Cervantes VR, De La Torre SJF. Adición de la proteína de choque térmico HSC70 en medios de cultivo sobre la producción in vitro de embriones bovinos. Reunión Nacional de Investigación Pecuaria, Chiapas, México: 2019:120-122. 
162. Virrueta MLM. Evaluación de dos sistemas de cultivo in vitro de embriones bovinos [tesis licenciatura]. Saltillo, Coahuila, México: Universidad Autónoma Agraria Antonio Narro; 2018.

163. Morales PF. Viabilidad post-criopreservación de embriones bovinos producidos in vitro y vitrificados mediante las técnicas de "open pulled straw" y cryotop [tesis maestría]. Ciudad de México, México; Universidad Nacional Autónoma de México; 2013.

164. Ahuja AC, Montiel PF, Pérez HP, Gallegos SJ. Medio alternativo para la producción in vitro de embriones bovinos. Zootecnia Trop 2009;27(3):277-284.

165. Martínez GO, Antillón RJ, Rodríguez AFA. Tasa de fertilización, desarrollo y calidad de embriones bovinos Holstein producidos in vitro con semen sexado y adición de IGFI. Tecnociencia Chihuahua 2020;9(3):140-147.

166. Van der Valk J, Brunner D, De Smet K, Svenningsen ÅF, Honegger P, Knudsen LE, et al. Optimization of chemically defined cell culture media-replacing fetal bovine serum in mammalian in vitro methods. Toxicol In vitro 2020;24(4):1053-1063.

167. Sovernigo TC, Adona PR, Monzani PS, Guemra S, Barros FDA, Lopes FG, et al. Effects of supplementation of medium with different antioxidants during in vitro maturation of bovine oocytes on subsequent embryo production. Reprod Dom Anim 2017;52(4):561569.

168. Torres V, Hamdi M, Millán de la Blanca MG, Urrego R, Echeverri J, López-Herrera A, et al. Resveratrol-cyclodextrin complex affects the expression of genes associated with lipid metabolism in bovine in vitro produced embryos. Reprod Dom Anim 2018;53(4):850-858.

169. Moore K, Rodriguez-Sallaberry CJ, Kramer JM., Johnson S, Wroclawska E, Goicoa S, et al. In vitro production of bovine embryos in medium supplemented with a serum replacer: effects on blastocyst development, cryotolerance and survival to term. Theriogenology 2007;68(9):1316-1325.

170. Do VH, Catt S, Kinder JE, Walton S, Taylor-Robinson AW. Vitrification of in vitro derived bovine embryos: targeting enhancement of quality by refining technology and standardising procedures. Reprod Fert Dev 2019;31(5):837-846.

171. Westhusin ME, Pryor JH, Bondioli KR. Nuclear transfer in the bovine embryo: a comparison of 5-day, 6-day, frozen-thawed, and nuclear transfer donor embryos. Mol Reprod Dev 1991;28(2):119-23.

172. Houdebine LM. Transgenic animal production. In: Ram LS, Sukanta M editors. Biotechnology for sustainable agriculture. UK: Woodhead Publishing; 2018:141-184. 
173. Tan W, Proudfoot C, Lillico SG, Whitelaw CBA. Gene targeting, genome editing: from Dolly to editors. Transgenic Res 2016;25:273-287.

174. Yum SY, Youn KY, Choi WJ, Jang G. Development of genome engineering technologies in cattle: from random to specific. J Animal Sci Biotechnol 2018;9:1-9. 